\title{
Proteomic Survey Reveals Altered Energetic Patterns and Metabolic Failure Prior to Retinal Degeneration
}

\author{
Ana Griciuc, ${ }^{1}$ Michel J. Roux, ${ }^{2}$ Juliane Merl, ${ }^{1}$ Angela Giangrande, ${ }^{3}$ Stefanie M. Hauck, ${ }^{1}$ Liviu Aron, ${ }^{4}$ and \\ Marius Ueffing ${ }^{1,5}$ \\ ${ }^{1}$ Research Unit Protein Science, Helmholtz Zentrum München (GmbH)-German Research Center for Environmental Health, D-85764 Neuherberg, \\ Germany, ${ }^{2}$ Department of Translational Medicine and Neurogenetics and ${ }^{3}$ Department of Development and Stem Cells, Institut de Génétique et de Biologie \\ Moléculaire et Cellulaire, CNRS UMR 7104 -INSERM U964-Université de Strasbourg, 67404 Illkirch, France, ${ }^{4}$ Department of Genetics, Harvard Medical \\ School, Boston, Massachusetts 02115 , and ${ }^{5}$ Center for Ophthalmology, Institute for Ophthalmic Research, University of Tübingen, 72076 Tübingen, Germany
}

Inherited mutations that lead to misfolding of the visual pigment rhodopsin (Rho) are a prominent cause of photoreceptor neuron (PN) degeneration and blindness. How Rho proteotoxic stress progressively impairs PN viability remains unknown. To identify the pathways that mediate Rho toxicity in PNs, we performed a comprehensive proteomic profiling of retinas from Drosophila transgenics expressing Rh1 ${ }^{\mathrm{P} 37 \mathrm{H}}$, the equivalent of mammalian Rho ${ }^{\mathrm{P} 23 \mathrm{H}}$, the most common Rho mutation linked to blindness in humans. Profiling of young Rh1 ${ }^{\mathrm{P} 37 \mathrm{H}}$ retinas revealed a coordinated upregulation of energy-producing pathways and attenuation of energy-consuming pathways involving target of rapamycin (TOR) signaling, which was reversed in older retinas at the onset of PN degeneration. We probed the relevance of these metabolic changes to PN survival by using a combination of pharmacological and genetic approaches. Chronic suppression of TOR signaling, using the inhibitor rapamycin, strongly mitigated PN degeneration, indicating that TOR signaling activation by chronic Rh1 ${ }^{\mathrm{P} 37 \mathrm{H}}$ proteotoxic stress is deleterious for PNs. Genetic inactivation of the endoplasmic reticulum stress-induced JNK/TRAF1 axis as well as the APAF-1/caspase- 9 axis, activated by damaged mitochondria, dramatically suppressed $\mathrm{Rh} 1{ }^{\mathrm{P} 37 \mathrm{H}}$-induced $\mathrm{PN}$ degeneration, identifying the mitochondria as novel mediators of Rh1 ${ }^{\mathrm{P} 37 \mathrm{H}}$ toxicity. We thus propose that chronic $\mathrm{Rh} 1{ }^{\mathrm{P} 37 \mathrm{H}}$ proteotoxic stress distorts the energetic profile of PNs leading to metabolic imbalance, mitochondrial failure, and $\mathrm{PN}$ degeneration and therapies normalizing metabolic function might be used to alleviate $\mathrm{Rh} 1^{\mathrm{P} 37 \mathrm{H}}$ toxicity in the retina. Our study offers a glimpse into the intricate higher order interactions that underlie PN dysfunction and provides a useful resource for identifying other molecular networks that mediate Rho toxicity in PNs.

Key words: metabolism; mitochondria; mTOR; proteomics; retinitis pigmentosa; rhodopsin

\section{Introduction}

Accumulation of misfolded proteins and the ensuing formation of protein aggregates are pervasive features of neurodegenerative disease. In most instances, the misfolded proteins start accumu-

\footnotetext{
Received July 13, 2013; revised Dec. 8, 2013; accepted Dec. 12, 2013.

Author contributions: A. Griciuc, S.M.H., L.A., and M.U. designed research; A. Griciuc, M.R., J.M., and L.A. performed research; A. Giangrande and S.H. contributed unpublished reagents/analytic tools; A. Griciuc, M.R., J.M., S.M.H., L.A., and M.U. analyzed data; A. Griciuc, L.A., and M.U. wrote the paper.

This study was supported by the European Community's Sixth Framework Program FP6 under grant agreement NEUROTRAIN (MEST-CT-2005-020235), the European Community's Seventh Framework Program FP7/2009 SYSCILIA under grant agreement number HEALTH-F5-2010-241955, and funds from the German Federal Ministry of Science and Education (BMBF) SysTec DYNAMO under grant agreement 0315513A. We thank Rüdiger Klein (MaxPlanck Institute of Neurobiology, Munich-Germany) for providing training and for stimulating discussions. We are grateful to our fly (B.A. Hay, H. Steller, and J. Chung) and antibody (H.D. Ryoo, A. Huber, N.J. Colley, C. Montell, C.V. Nicchitta, and D.R. Alessi) donators. We thank Sandra Helm and Silke Becker for excellent technical assistance and Marcel Blindert for scripting. We thank Luise Jennen (Institute of Pathology, Helmholtz Zentrum Muenchen) for assistance with electron microscopy and the Ueffing lab for discussions.

The authors declare no financial interests or conflict of interest.

Correspondence should be addressed to Liviu Aron, Department of Genetics, Harvard Medical School, Boston, MA 02115, E-mail: liviu@hms.harvard.edu; or Marius Ueffing, Center for Ophthalmology, Institute for Ophthalmic Research, University of Tübingen, 72076 Tübingen, Germany, E-mail: marius.ueffing@uni-tuebingen.de.

A. Griciuc's present address: Genetics and Aging Research Unit, Massachusetts General Hospital and Harvard Medical School, Charlestown, MA 02129.

DOI:10.1523/JNEUROSCI.2982-13.2014

Copyright $\odot 2014$ the authors $\quad 0270-6474 / 14 / 342797-16 \$ 15.00 / 0$
}

lating decades before the clinical onset of symptoms, begging the question of how neurons can tolerate chronic proteotoxic stress. Accumulation of misfolded rhodopsin (Rho) in photoreceptor neurons (PNs) of the retina leads to retinitis pigmentosa (RP), a subtype of retinal dystrophy characterized by progressive loss of visual abilities leading to blindness. Mutations in $>190$ genes cause retinal degeneration (RD), making it the most complex genetic disease in man (Daiger et al., 2007). The most common mutations associated with RP are those that lead to Rho misfolding (Daiger et al., 2007; Bramall et al., 2010; Wright et al., 2010). The major, unresolved, question is how these abnormal Rho species lead to progressive dysfunction and degeneration of PNs.

Substitution of proline 23 by histidine in the visual pigment Rho $\left(\mathrm{Rho}^{\mathrm{P} 23 \mathrm{H}}\right.$ ) generates a folding-deficient Rho variant that exhibits increased retention in the endoplasmic reticulum (ER) and self-aggregates (Illing et al., 2002; Saliba et al., 2002; Mendes et al., 2005). Studies in Drosophila melanogaster also revealed that misfolded Rh1 is retained in the ER, leading to ER expansion (Colley et al., 1995) and ER stress (Galy et al., 2005; Ryoo et al., 2007; Griciuc et al., 2012). We have recently found that misfolded Rho is cleared, both in mammalian cells (Griciuc et al., 2010a) and fly PNs (Griciuc et al., 2010b), by a process called ERassociated degradation (ERAD). Misfolded Rho interacts with 
the chaperone $\mathrm{VCP} /$ ter94, a major effector of the ERAD pathway, which promotes its extraction from the ER and proteasomal degradation (Griciuc et al., 2010a). Inhibition of VCP function, or attenuation of proteasome activity, strongly mitigates $\mathrm{Rh} 1^{\mathrm{P} 37 \mathrm{H}}$ induced PN degeneration, suggesting that excessive ERAD is pathogenic for PNs (Griciuc et al., 2010b). In mice expressing $\mathrm{Rho}^{\mathrm{P} 23 \mathrm{H}}$ and undergoing RD, Rho localized to both ER and plasma membrane; however, $90 \%$ of the mutant protein was cleared (Sakami et al., 2011), probably by ERAD.

How chronic ER stress and ERAD impact the cellular networks in PNs and engage the cell death machineries remains unknown (Griciuc et al., 2011). We hypothesized that trapping of misfolded Rho in the ER and chronic activation of ER stress/ ERAD pathways exerts a distorting effect on multiple cellular pathways causing severe imbalances in critical homeostatic processes. To unravel such critical networks, we performed the first large-scale proteomic profiling of Drosophila melanogaster retinas expressing the Rho ${ }^{\mathrm{P} 23 \mathrm{H}}$ equivalent mutation Rh1 ${ }^{\mathrm{P} 37 \mathrm{H}}$. We uncovered an early upregulation of energy-producing pathways and attenuation of target of rapamycin (TOR) signaling, which were reversed at the onset of RD. Complementary pharmacological experiments suggest that chronic suppression of TOR signaling confers long-term protection against $\mathrm{RD}$. Genetic analyses further suggest that chronic Rh1 proteotoxicity causes mitochondrial failure and activation of the APAF-1/caspase-9 pro-apoptotic axis, thus identifying the mitochondria as critical mediators of Rh1 proteotoxicity. We suggest that energetic and metabolic dysfunction represent a critical link between Rho misfolding/proteotoxicity and PN degeneration in RP.

\section{Materials and Methods}

Fly stocks, crosses, and rearing. Drosophila lines $p\left(w^{+} ; R h 1-R h 1^{W T}\right)$ and $p\left(w^{+} ; R h 1-R h 1^{P 37 H}\right)$ referred to as $R h 1^{W T}$ and $R h 1^{P 37 H}$, respectively, were previously described (Galy et al., 2005). Control flies were either wildtype (WT) or Rh1-Gal4 flies. DTRAF1 ${ }^{\text {exl }}$ referred to as $T r a f 1^{L O F}$ was a kind gift from J. Chung (Cha et al., 2003). Ice $\Delta 1$ referred to as Ice ${ }^{L O F}$ was kindly provided by B.A. Hay (Muro et al., 2006). HidA206 referred to as $\mathrm{Hid}^{L O F}$ was a kind gift from H. Steller (Sandu et al., 2010). Bsk1 (stock no. 3088) referred to as $b s k 1^{L O F}, D a r k 82$ (stock no. 23285) referred to as Dark $^{L O F}$, Dronc51 (stock no. 23284) referred to as Dronc ${ }^{L O F}$ and $w^{1118}$ (stock no. 5905) flies were from the Bloomington stock center. Flies were raised on standard cornmeal agar medium, under moderate continuous illumination at $25^{\circ} \mathrm{C}$. Moderate illumination was obtained by using photosynthetic fluorescent tubes (in total $170 \mathrm{~cd} / \mathrm{m}^{2}$ ). All experimental groups included male and female flies (ratio 1:1). Fly progeny having same eye pigmentation was used throughout the study.

1D prefractionation of lysates. After $2 \mathrm{~d}$ or $14 \mathrm{~d}$ of light exposure, 200 retinas were collected separately for each genotype and lysed in detergentcontaining radioimmunoprecipitation assay (RIPA)-modified buffer (20 mм Tris- $\mathrm{HCl}, \mathrm{pH} 8.0,150 \mathrm{~mm} \mathrm{NaCl}, 1$ mм EDTA, 1\% Triton X-100, $0.1 \%$ SDS, and $0.5 \%$ sodium deoxycholate) supplemented with protease inhibitors (Roche) and phosphatase inhibitors (Sigma-Aldrich). Lysates were centrifuged at $16,000 \times g$ for $15 \mathrm{~min}$ at $4^{\circ} \mathrm{C}$ and the supernatants were kept for further analysis. The protein concentration of the lysates was measured using the DC protein kit based on the Lowry assay (BioRad). For each postnatal day 2 and 14 (P2 and P14), three replicates for both Rh1 ${ }^{\mathrm{WT}}$ and $\mathrm{Rh} 1^{\mathrm{P} 37 \mathrm{H}}$ (80 $\mu \mathrm{g}$ per lane) were loaded on a $4-15 \%$ precast gradient gel (TGX; Bio-Rad). After separation, the gel was fixed and stained using Coomassie dye (0.1\% Coomassie Brilliant Blue R-250 in 50\% methanol, $10 \%$ acetic acid). Each lane was cut into six bands corresponding to different molecular weights to allow sample prefractionation. Every band was subjected to in-solution tryptic digestion and subsequent nano-LC-MS/MS analysis.

In-gel digest with trypsin. Excised bands of the prefractionation gel were cut in cubes of $1 \mathrm{~mm}^{3}$ and transferred into tubes (Eppendorf). After destaining the gel cubes for 10 min with $200 \mu \mathrm{l}$ of $60 \%$ acetonitrile (ACN) and a 10 min wash using $200 \mu \mathrm{H}_{2} \mathrm{O}$, the pieces were dehydrated using $200 \mu \mathrm{l}$ of $100 \%$ ACN for $10 \mathrm{~min}$. For protein reduction, $100 \mu \mathrm{l}$ of $5 \mathrm{~mm}$ dithiothreitol (DTT) was added and incubated for $15 \mathrm{~min}$ at $60^{\circ} \mathrm{C}$. After removal of DTT and dehydration using $100 \% \mathrm{ACN}, 100 \mu \mathrm{l}$ of freshly prepared $25 \mathrm{~mm}$ iodoacetamide solution was added for $15 \mathrm{~min}$ at room temperature in the dark. The gel pieces were washed for $5 \mathrm{~min}$ with $100 \mu \mathrm{l}$ $\mathrm{H}_{2} \mathrm{O}$ and again dehydrated in $100 \% \mathrm{ACN}$ for $10 \mathrm{~min}$. After three wash steps of 10 min with $50 \mathrm{~mm}$ ammonium bicarbonate $(\mathrm{ABC}), 60 \% \mathrm{ACN}$, and $100 \% \mathrm{ACN}$, the gel cubes were air dried for $15 \mathrm{~min}$ at $37^{\circ} \mathrm{C}$. One hundred microliters of a $0.01 \mu \mathrm{g} / \mu \mathrm{l}$ trypsin solution (Promega) in $50 \mathrm{~mm}$ $\mathrm{ABC}$ was added to the gel cubes and incubated for $10 \mathrm{~min}$, and $25 \mathrm{~mm}$ $\mathrm{ABC}$ was added to cover the gel pieces completely during the digest at $37^{\circ} \mathrm{C}$ overnight $(\mathrm{o} / \mathrm{n})$. For elution, $100 \mu \mathrm{l}$ of $60 \%$ ACN $/ 0.1 \%$ TFA were added to the gel cubes and incubated for $15 \mathrm{~min}$. The supernatant was transferred to a new tube and $100 \mu \mathrm{l}$ of $99.9 \%$ ACN/0.1\% TFA was added to the gel pieces. After $30 \mathrm{~min}$ of incubation, the supernatants containing the eluted peptides were pooled, dried in a speedvac (UniEquip), and stored at $-20^{\circ} \mathrm{C}$.

MS. Dried digested samples were thawed and dissolved in 2\% ACN/ $0.5 \%$ TFA. The samples were centrifuged for $5 \mathrm{~min}$ at $4^{\circ} \mathrm{C}$. LC-MS/MS analysis was performed as described previously (Hauck et al., 2010). Every sample was automatically injected and loaded onto the trap column at a flow rate of $30 \mu \mathrm{l} / \mathrm{min}$ in $5 \%$ buffer B (98\% ACN $/ 0.1 \%$ formic acid (FA) in HPLC-grade water) and 95\% buffer A ( $2 \%$ ACN/0.1\% FA in HPLC-grade water). After $5 \mathrm{~min}$, the peptides were eluted from the trap column and separated on the analytical column by a 170 min gradient from 5 to $31 \%$ of buffer B at $300 \mathrm{nl} / \mathrm{min}$ flow rate followed by a short gradient from 31 to $95 \%$ buffer B in 5 min. Between each sample, the gradient was set back to $5 \%$ buffer B and left to equilibrate for $20 \mathrm{~min}$. From the MS prescan, the 10 most abundant peptide ions were fragmented in the linear ion trap if they showed an intensity of at least 200 counts and if they were at least +2 charged. During fragmentation a high-resolution (60,000 full-width half maximum) MS spectrum was acquired in the LTQ Orbitrap XL (Thermo Scientificwith a mass range from 200 to $1500 \mathrm{Da}$.

Label-free analysis. Protein expression levels in $R h 1^{P 37 H}$ flies were compared relative to $R h 1^{W T}$ flies using a label-free LC-MS/MS-based strategy. Quantitative analysis was performed using the Progenesis LC-MS and Max-Quant software. Prefractionation improves the limits of quantification in complex samples, but is thought to potentially influence the accuracy of label-free quantifications (Bantscheff et al., 2007). Therefore, the technical variability of sample preparation was determined, including the MS measurements, expressed as coefficient of variation (CV). CV was $<14 \%$ for the Progenesis and $<24 \%$ for the MaxQuant analyses, confirming robust sample preparation, prefractionation, and MS analysis.

Label-free analysis using Progenesis LC-MS. The acquired spectra were loaded to the Progenesis LC-MS software (version 2.5, Nonlinear) for label-free quantification and analyzed as described previously (Hauck et al., 2010; Merl et al., 2012). Features with only one charge or more than eight charges were excluded. Raw abundances of the remaining features were normalized to allow correction for factors resulting from experimental variation. Rank 1-3 MS/MS spectra were exported as Mascot generic file and used for peptide identification with Mascot (version 2.2) in the Ensembl Drosophila protein database (13136213 residues, 21886 sequences). Search parameters were as follows: $10 \mathrm{ppm}$ peptide mass and 0.6 Da MS/MS tolerance, one missed cleavage allowed, carbamidomethylation as fixed modification, and methionine oxidation and asparagine/glutamine deamidation as variable modifications. A Mascotintegrated decoy database search calculated a false discovery rate of $<1.4 \%$, using an ion score cutoff of 30 and a significance threshold of $p<$ 0.01 for all searches. Peptide assignments were re-imported into the Progenesis software. After summing up the abundances of all peptides allocated to each protein, the results of all fractions were combined to a total analysis set and grouped (WT vs P37H). Total normalized protein abundance values in all fractions were used for statistical calculations.

After alignment and data normalization all samples were allocated to their respective groups (Rh1 ${ }^{\mathrm{WT}}$ or $\mathrm{Rh} 1^{\mathrm{P} 37 \mathrm{H}}$ ) for both the $\mathrm{P} 2$ and the $\mathrm{P} 14$ analysis. The Progenesis LC-MS analyses provided a total of 2710 or 2046 protein identifications at $\mathrm{P} 2$ and $\mathrm{P} 14$, respectively. After filtering of pro- 
teins identified and quantified with $<2$ peptides, the list was narrowed down to 1916 and 1485 proteins, respectively. In the Student's $t$ test analysis comparing Rh1 $1^{\text {WT }}$ and Rh1 ${ }^{\mathrm{P} 37 \mathrm{H}}$ mutant samples, 225 (P2) and 186 (P14) proteins reached a $p$ value of 0.05 or below.

Label-free analysis using MaxQuant. The raw files were loaded into the 1.2.0.13 version of the MaxQuant software (Max Planck Institute of Biochemistry, Martinsried; Cox and Mann, 2008; Cox et al., 2009) with its internal search engine Andromeda (Cox et al., 2011). Except for the precursor tolerance of $10 \mathrm{ppm}$, all settings were set as default and "multiplicity" was set to one. The Andromeda search engine was configured for the Ensembl Drosophila protein database. The software further includes a decoy database to determine the false discovery rate, as well as a common contaminants database to exclude false positive hits due to contamination. Feature-matching between raw files was enabled, using a retention time window of $2 \mathrm{~min}$. "Discard unmodified counterpart peptides" was unchecked. Averaged label-free quantification intensity values were used for statistical analysis.

Through MaxQuant analysis, a total of 2931 protein groups were identified in the P2 analysis and 2327 in P14. After filtering, the list was reduced to 2518 or 2053 proteins, respectively. Of these, 266 (at P2) and 249 (at P14) protein groups showed significantly different abundance comparing Rh1 ${ }^{\mathrm{WT}}$ and Rh1 ${ }^{\mathrm{P} 37 \mathrm{H}}$ mutant samples $(p<0.05)$.

Pathway enrichment analysis. With the lists of significantly altered proteins, pathway enrichment analyses were performed, separately for the upregulated and downregulated proteins in the $R h 1^{P 37 H}$ mutant (relative to $R h 1^{W T}$ ) at P2 or P14. We used the Ingenuity Pathway Analysis (IPA) tool (http://ingenuity.com/products/pathways_analysis.html) to obtain the overrepresented pathways of all four protein sets.

Histology, toluidine blue staining, and analysis. Fly heads were dissected and postfixed in $2.5 \%$ glutaraldehyde in PBS overnight at $4^{\circ} \mathrm{C}$. After washing with PBS, heads were incubated in $1 \%$ osmium tetraoxide solution (Science Services) and then dehydrated in ethanol solutions of increasing concentrations (25-100\%), followed by $10 \mathrm{~min}$ incubation in propylene oxide (Sigma-Aldrich). Heads were then incubated overnight in a solution containing 50\% propylene oxide and 50\% Durcupan epoxy resin mixture. The epoxy resin mixture consisted of $48 \%$ Component A/M, 40\% Hardener B, 2.25\% Accelerator C, and 9\% Plasticizer D (Sigma-Aldrich). Then, heads were incubated o/n in 100\% Durcupan epoxy resin mixture. The next day, heads and fresh Durcupan epoxy resin mixture were transferred to molds; heads were oriented tangentially and cooked overnight at $60^{\circ} \mathrm{C}$. The polymerized resin containing the specimens was cut using an ultramicrotome. Semithin sections of $2 \mu \mathrm{m}$ were collected, mounted, and then stained with toluidine blue solution $(0.1 \%$ toluidine blue, $2.5 \%$ sodium carbonate). Pictures at different retinal depths were acquired for each head at $40 \times$ magnification. To determine the number of photoreceptor neurons/ommatidium (P/O), at least 150 ommatidia were scored per animal from at least six animals per genotype.

Electron microscopy. For electron microscopy, the specimens were embedded the same way as described above for toluidine blue staining experiments. Subsequently, $70 \mathrm{~nm}$ ultrathin sections (instead of $2 \mu \mathrm{m}$ ) were collected on nickel grids and contrasted with 5\% uranyl acetate and lead citrate, and analyzed with a Zeiss electron microscope EM 10.

Western blotting. Fly heads were homogenized in RIPA-modified buffer $(20$ mм Tris-HCl, pH 8.0, $150 \mathrm{~mm} \mathrm{NaCl}, 1 \mathrm{~mm}$ EDTA, 1\% Triton $\mathrm{X}-100,0.1 \%$ SDS, and $0.5 \%$ sodium deoxycholate) supplemented with protease inhibitors (Roche) and phosphatase inhibitors (Sigma-Aldrich). Lysates were centrifuged at $16,000 \times g$ for $15 \mathrm{~min}$ at $4^{\circ} \mathrm{C}$ and the supernatants containing detergent-soluble fractions were kept for further analysis. Samples were normalized for total protein using the DC protein kit (Bio-Rad) based on Lowry assay. An equal volume of $2 \times$ SDS sample buffer was added to samples that were separated by $1 \mathrm{~mm}$ thick gels for $10-12 \%$ SDS-PAGE and electroblotted onto PVDF membranes (GE Healthcare). Immunodetection was performed according to standard techniques using the following primary antibodies: anti-Rh1 (4C5, mouse monoclonal, 1/5000; Developmental Studies Hybridoma Bank), anti-Hsc3 (guinea pig, 1/2000; gift from H.D. Ryoo; Ryoo et al., 2007), anti-TRP (rabbit polyclonal, 1/10,000; gift from A. Huber; Voolstra et al., 2010), anti-INAD (rabbit polyclonal, 1/10,000; gift from C. Montell; Lee and Montell, 2004), anti-Calnexin (rabbit polyclonal, 1/5000; gift from
N.J. Colley; Rosenbaum et al., 2006), anti-Gp93 (rabbit polyclonal, 1/10,000; gift from C.V. Nicchitta; Maynard et al., 2010), anti-mt-ND1 (rabbit polyclonal, 1/200; Abcam), anti-phospho-4E-BP1 (Thr37/46, rabbit monoclonal, 1/1000; Cell Signaling Technology), anti-4E-BP1 (rabbit monoclonal, 1/1000; Cell Signaling Technology), anti-phospho-Drosophila p70S6K kinase (Thr398, rabbit polyclonal, 1/1000; Cell Signaling Technology), anti-p70S6K (rabbit polyclonal, 1/500; generated by D.R. Alessi, University of Dundee, UK; Lizcano et al., 2003), and anti- $\beta$-Tubulin (mouse monoclonal, 1/4000; Millipore Bioscience Research Reagents). Secondary antibodies were horseradish peroxidase-coupled (1/8000; Jackson ImmunoResearch). Quantification of band intensity after ECL detection was performed using Image Quant TL software.

Pharmacological treatments. Flies were treated with rapamycin (SigmaAldrich) or the JNK inhibitor-SP600125 (Calbiochem-Millipore) dissolved in fly food. Two doses of rapamycin (50 and $200 \mu \mathrm{M}$, final concentration in fly food) and two doses of SP600125 (200 $\mu \mathrm{M}$ and $1 \mathrm{mM}$, final concentration in fly food) were used. These compounds were first dissolved in dimethylsulfoxide (DMSO) and the resulting solution was then added to fly food cooled down to $30^{\circ} \mathrm{C}$. Flies were transferred to vials containing modified food right after eclosion, were reared as described above, and transferred to fresh vials every day. The control food contained all the ingredients (including DMSO) except the active compound. After $30 \mathrm{~d}$ of light exposure, flies were collected and their retinal integrity was assessed histologically.

Electroretinogram analysis. Cold-anesthetized flies were immobilized in clay. A tungsten electrode (0.5-1 M $\Omega$; Intracell) was inserted into the posterior part of the head and a glass electrode filled with $3 \mathrm{M} \mathrm{KCl}(2-6 \mathrm{M} \Omega)$ was poked through the cornea. Flies were dark adapted for $2 \mathrm{~min}$ before recordings. An orange LED (591 nm, LY 5436-VBW-1; Osram) was placed at $1 \mathrm{~cm}$ from the head. The flash intensity reaching the eye was $650 \mu \mathrm{W} / \mathrm{cm}^{2}$, as measured with a PM100D power meter and S121C photodiode (Thorlabs). Six light pulses were applied and the recorded responses were averaged. Flash intensity and duration were controlled through pClamp and the Digidata analog output. Signals were filtered at $2 \mathrm{kHz}$ and digitized at $10 \mathrm{kHz}$, using a MultiClamp 700A amplifier, a Digidata 1322A interface, and pClamp-8 software (Molecular Devices).

Statistical analysis. Data were evaluated and statistics were performed using Excel software (Microsoft Office 2003 SP3). MaxQuant data were filtered for reverse identifications, contaminants, and "only identified by site." All identifications in both analyses based on $<2$ unique peptides were eliminated. In both quantification approaches we performed a twosided Student's $t$ test using the normalized abundances of the identified proteins.

\section{Results}

\section{Proteomic profiling of $R h 1$ transgenic flies}

To explore the pathways linking Rho proteotoxic stress to PN degeneration in RP, we undertook a label-free LC-MS/MS-based comparative proteomic analysis of a Drosophila model expressing $\mathrm{Rh} 1^{\mathrm{P} 37 \mathrm{H}}$ (the equivalent of the most common RP-linked mutation, Rho $\left.{ }^{\mathrm{P} 23 \mathrm{H}}\right)$. We chose $R h 1^{W T}$ flies as the most appropriate control for $R h 1^{P 37 H}$ flies, to eliminate any confounding effects due to Rh1 overexpression. In both of these lines, transgenic $R h 1$ expression is driven by a promoter that mimics the endogenous $R h 1$ promoter (Galy et al., 2005; Griciuc et al., 2010b). As a result, both $R h 1^{P 37 H}$ and $R h 1^{W T}$ flies express moderate and equivalent levels of transgenic Rh1 (an additional 50\% relative to the endogenous Rh1, totaling 150\% Rh1 in their retinas; Griciuc et al., 2010b). Furthermore, we chose to perform this proteomic analysis in flies exposed to light for $2 \mathrm{~d}$ or $14 \mathrm{~d}$ after eclosion (corresponding to P2 and P14, respectively). $R h 1^{P 37 H}$ flies have a largely preserved retinal structure at P14, and a normal complement of PNs, but do display the first signs of RD, such as vacuoles and disturbed rhabdomere morphology (Galy et al., 2005 and see below). 


\section{Protein identification and quantification}

The analysis of $\mathrm{Rh} 1{ }^{\mathrm{P} 37 \mathrm{H}}$ and $\mathrm{Rh} 1{ }^{\mathrm{WT}}$ proteomes at $\mathrm{P} 2$ and $\mathrm{P} 14$ by label-free LC-MS/MS was performed using the MaxQuant quantitative proteomics software (Cox and Mann, 2008) and the Progenesis LC-MS platform (Hauck et al., 2010; Merl et al., 2012). Compilation of the Progenesis and MaxQuant data identified a total of 409 proteins whose levels were significantly altered in the $R h 1^{P 37 H}$ mutant at $\mathrm{P} 2$. Of these, 204 proteins were found to be more abundant in the $R h 1^{P 37 H}$ mutant and 205 proteins showed decreased levels in the $R h 1^{P 37 H}$ mutant. Of the 350 significantly different proteins at $\mathrm{P} 14,132$ were less abundant and 218 proteins were more abundant in the $R h 1^{P 37 H}$ mutant (data not shown).

\section{Early upregulation of energy-producing pathways in the $\boldsymbol{R h} 1^{P 37 H}$ retina}

To identify proteomic changes that show coordinated coregulation (i.e., networks), we performed a network analysis on the proteomic data using the IPA software (Thiele et al., 2012). The IPA analysis includes only those Drosophila genes with functional homology to their mammalian counterparts. When applying the IPA to identify cellular networks that were induced in 2-d-old $R h 1^{P 37 H}$ flies (relative to $R h 1^{W T}$ flies) we found a striking upregulation of energy-producing pathways, which included the glycolysis, the citric acid (Krebs) cycle, and oxidative phosphorylation (Table 1, Fig. $1 A)$. Numerous proteins functioning in the respiratory chain complex I (NADH-coenzyme Q reductase; such as NDUFS1, NDUFV2, NDUFS8, NDUFS2, NDUFB8, NDUFB10, and NDUFS4) and complex IV (COX6A1) as well as those linked to ATPase function and ATP production (ATP6V1E1, ATP5H, and ATP5O) were upregulated in $R h 1^{P 37 H}$ retinas. The Parkinson's associated gene PARK7/DJ-1, encoding a major mitochondrially acting oxidative stress suppressor (Abou-Sleiman et al., 2006), was also upregulated.

Early downregulation of protein synthesis and ubiquitination pathways in the $R h 1^{P 37 H}$ retina

When analyzing the genes that were downregulated in 2-d-old $R h 1^{P 37 H}$ retinas, we found a strong enrichment for gene products involved in EIF2 and eIF4/p70S6K signaling. This included genes encoding eukaryotic translation initiation factors (EIF1, EIF2S3, EIF3A, EIF3H, EIF4A2, and EIF4G1) and ribosomal proteins (RPS3A, RPLO, RPS23, RPL38, and PSMB7). With the exception of EIF1, these proteins represent components or targets of TOR signaling, a master regulator of cellular metabolism, which coordinates the biogenesis of ribosomes with the initiation of translation and the regulation of protein degradation machineries (Kapahi et al., 2010; Thoreen et al., 2012; Table 1, Fig. 1B). Twoday-old $R h 1^{P 37 H}$ flies also featured a prominent downregulation of proteasome components (PSMD11, PSMD7, PSMC6, PSMD7, PSMC6, PSMD14, PSMD4, and PSMC3), suggesting an attenuation of cellular degradative processes.

Collectively, these results are consistent with an early increase in energy production, featuring a coordinated upregulation of both aerobic and anaerobic processes and oxidative phosphorylation, coupled to attenuation of energy-consuming processes, such as proteasome biogenesis and mRNA translation in retinas expressing Rh1 ${ }^{\mathrm{P} 37 \mathrm{H}}$.

\section{Upregulation of TOR signaling and oxidative stress response pathways at the onset of $\mathrm{RD}$}

When categorizing the proteomic changes in 14-d-old flies, we found an unexpected upregulation of several TOR-signaling components (Table 1, Fig. 2A). This upregulation involved the following: (1) the eukaryotic translation initiation factor EIF4G1, which interacts with EIF4E and is critical for TOR/4E-BP1mediated translational initiation (Thoreen et al., 2012) and might be phosphorylated downstream of TOR activation (Raught et al., 2000); (2) several ribosome components (RPS16, RPS18, RPLP2, RPS20, RPS25, RPL10A, and RPSA) whose translation was recently shown to depend on mTOR signaling activation (Thoreen et al., 2012); and (3) and other targets of TOR signaling (RHOC and PRKCA). We further detected an upregulation of caveolarmediated endocytosis and NRF2-mediated signaling, a major controller of oxidative stress responses in cells (Kensler et al., 2007; Table 1, Fig. 2A).

Downregulation of amino acid metabolism at the onset of RD Fourteen-day-old $R h 1^{P 37 H}$ displayed a coordinated downregulation of several metabolic pathways, including glutamate metabolism, amino acid biosynthesis, glycerophospholipid metabolism, and oxidative phosphorylation (Table 1, Fig. 2B). Notably, several components of the ATP production network (SDHB, ATP5A1, UQCRC2, and UQCRFS1) were downregulated in 14-d-old $R h 1^{P 37 H}$ retinas.

These results suggest that, in stark contrast to the situation seen in $\mathrm{P} 2$ retinas, $\mathrm{P} 14 R h 1^{\mathrm{P} 37 H_{-}}$-expressing retinas activate TOR signaling and its associated proteasome biogenesis and translation initiation, while exhibiting enhanced endocytosis and an increased oxidative stress response. This is accompanied by a suppression of amino acid and glycerophospholipid metabolism and oxidative phosphorylation, suggesting that dysfunctional neurons exhibit a deregulated (inversed) metabolic and energetic pattern at the onset of retinal degeneration. It is interesting to note that enhanced endocytosis has been identified as a critical pathogenic event in several models of RD (Griciuc et al., 2012). Collectively, these proteomics observations raise the possibility that chronic $\mathrm{Rh} 1{ }^{\mathrm{P} 37 \mathrm{H}}$ proteotoxic stress alters the pattern of energy consumption in PNs, leading to energy exhaustion and cellular and oxidative stress, and ultimately to cell death.

\section{Validation of the proteomics results}

We sought to validate our MS-based proteomic analysis by using a second independent method for protein quantification. We selected proteins for which antibodies were readily available and have been previously used for antigen detection by Western blotting in Drosophila. We tested the Rh1 protein; the rhabdomeric markers INAD and TRP; the mitochondrially encoded NADH dehydrogenase 1 (mt-ND1); and the ER chaperones Hsc3, Gp93, and Calnexin. The levels of these proteins in P2 and P14 Rh1 ${ }^{\mathrm{P} 37 \mathrm{H}}$ versus Rh1 ${ }^{\text {WT }}$ retinas-as assessed by Western blotting- showed a good correlation with those assessed by MS (Fig. 3). These results suggest that MS-based quantitation allows proper detection of proteomic alterations in Drosophila.

\section{Altered mitochondrial structure and dynamics in Rh1 ${ }^{\text {P37H }}$ PNs}

To analyze the cellular changes in the $R h 1^{P 37 H}$ retina with subcellular resolution, we performed electron microscopy studies on P14 flies (Fig. 4). This analysis revealed that retinal ultrastructure was grossly maintained in both $R h 1^{W T}$ and $R h 1^{P 37 H}$ flies, as evidenced by a normal complement of PNs (Fig. 4A,B). However, numerous rhabdomeres (lighttransducing organelles, containing Rh1) exhibited structural abnormalities, suggesting that mutant $\mathrm{Rh} 1^{\mathrm{P} 37 \mathrm{H}}$ causes rhabdomere structural defects. In agreement with previous observations (Colley et al., 1995), we also found a marked 


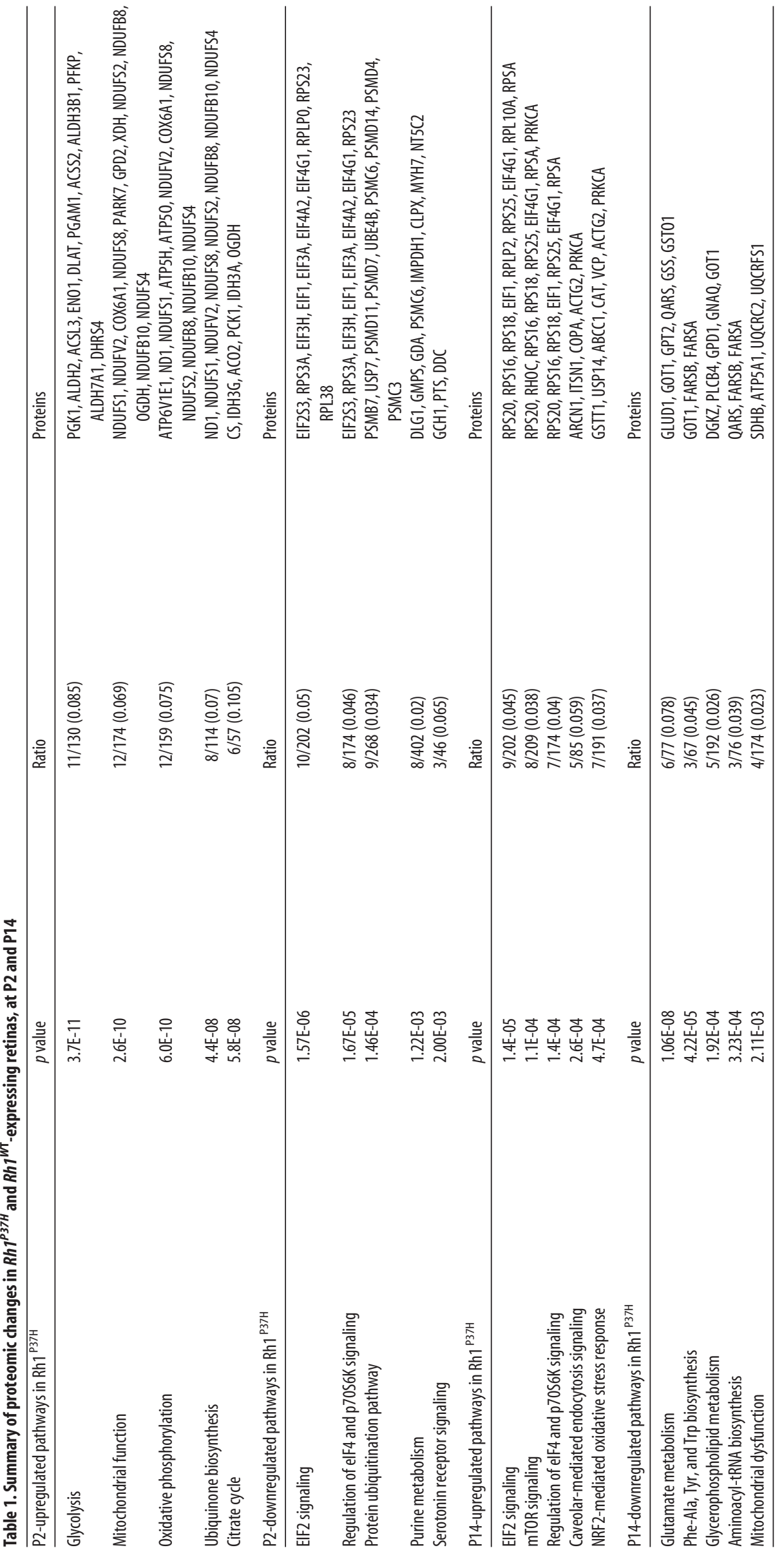


A
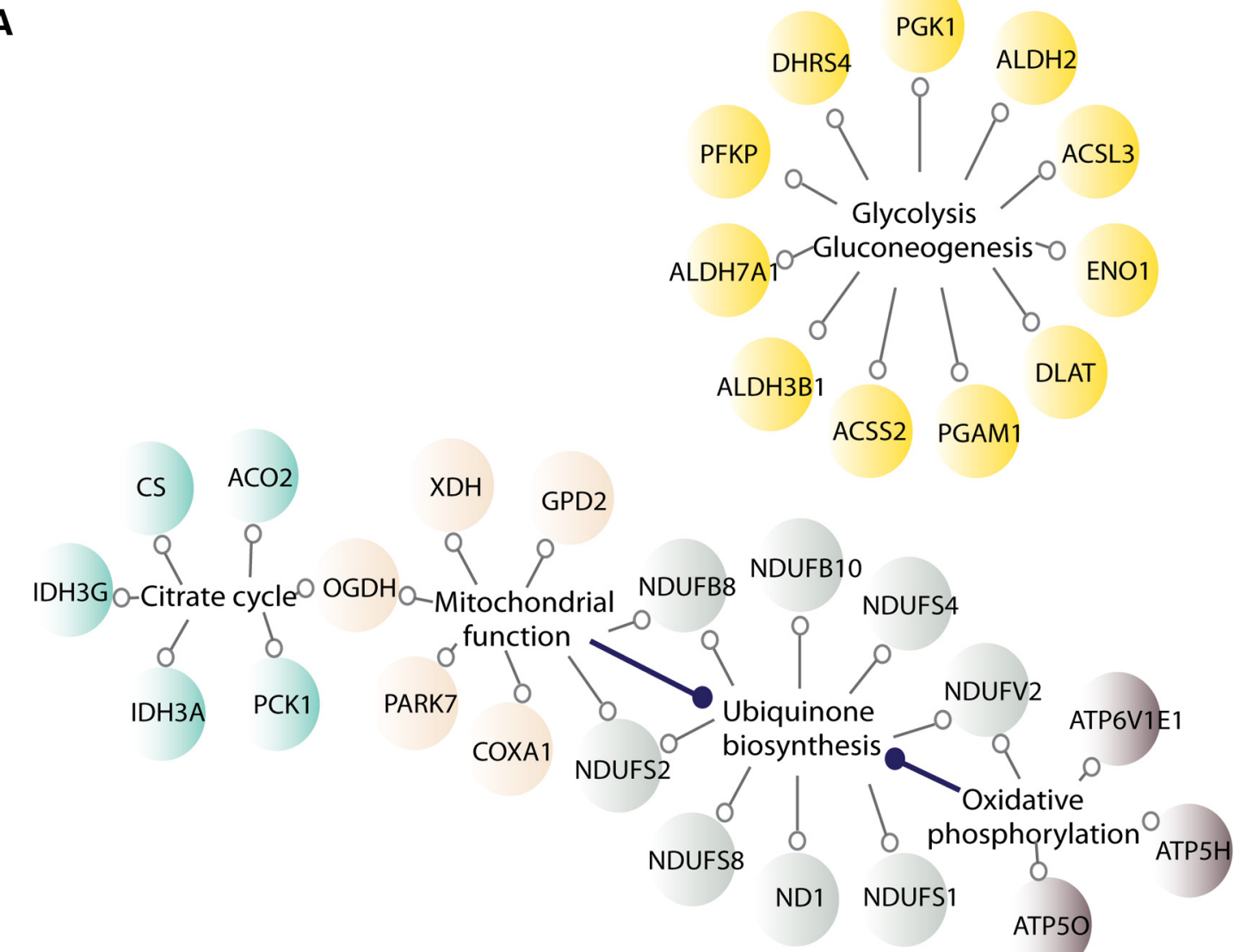

B
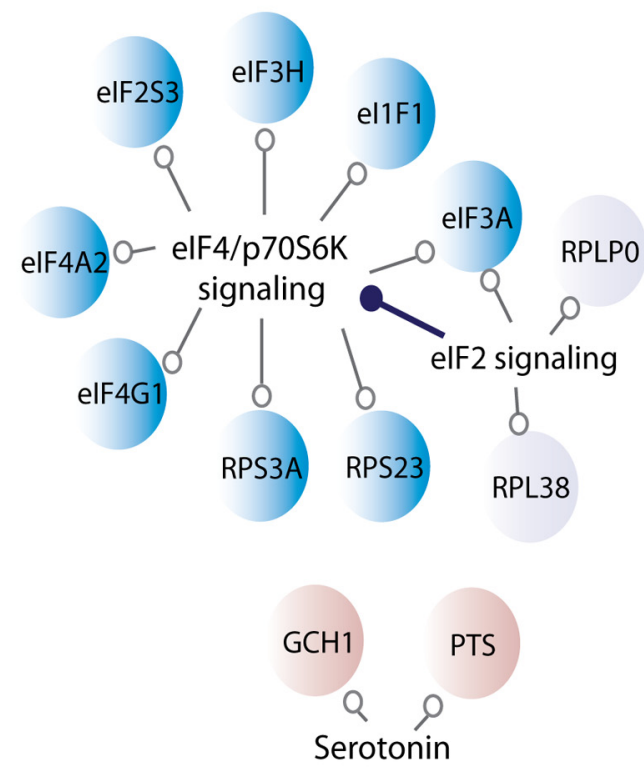

receptor signaling

DDC
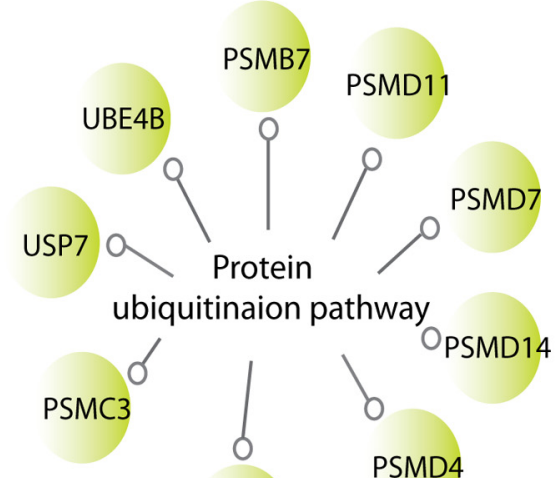

PSMC6

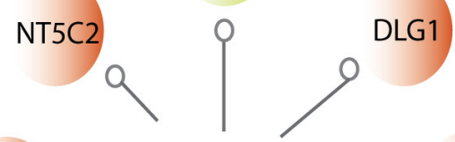

Purine

MYH7 O- metabolism $\longrightarrow$ GMPS

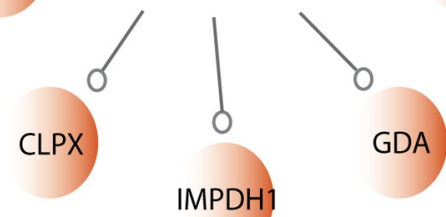

Figure 1. Protein networks upregulated $(\boldsymbol{A})$ and downregulated $(\boldsymbol{B})$ in the $R h 7^{\mathrm{P}_{3} \mathrm{HH}}$ retina, at $\mathrm{P} 2$. 
A

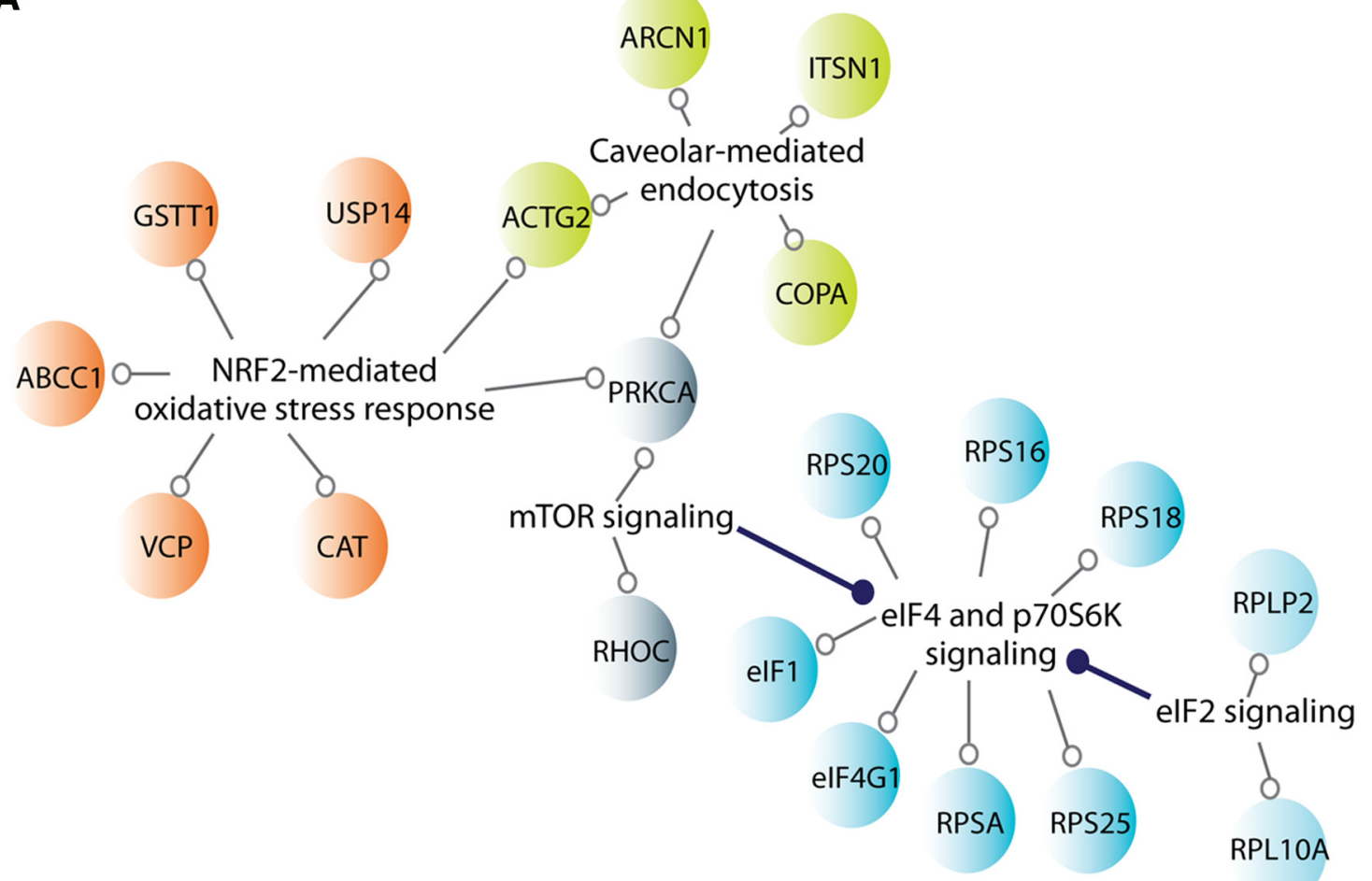

B

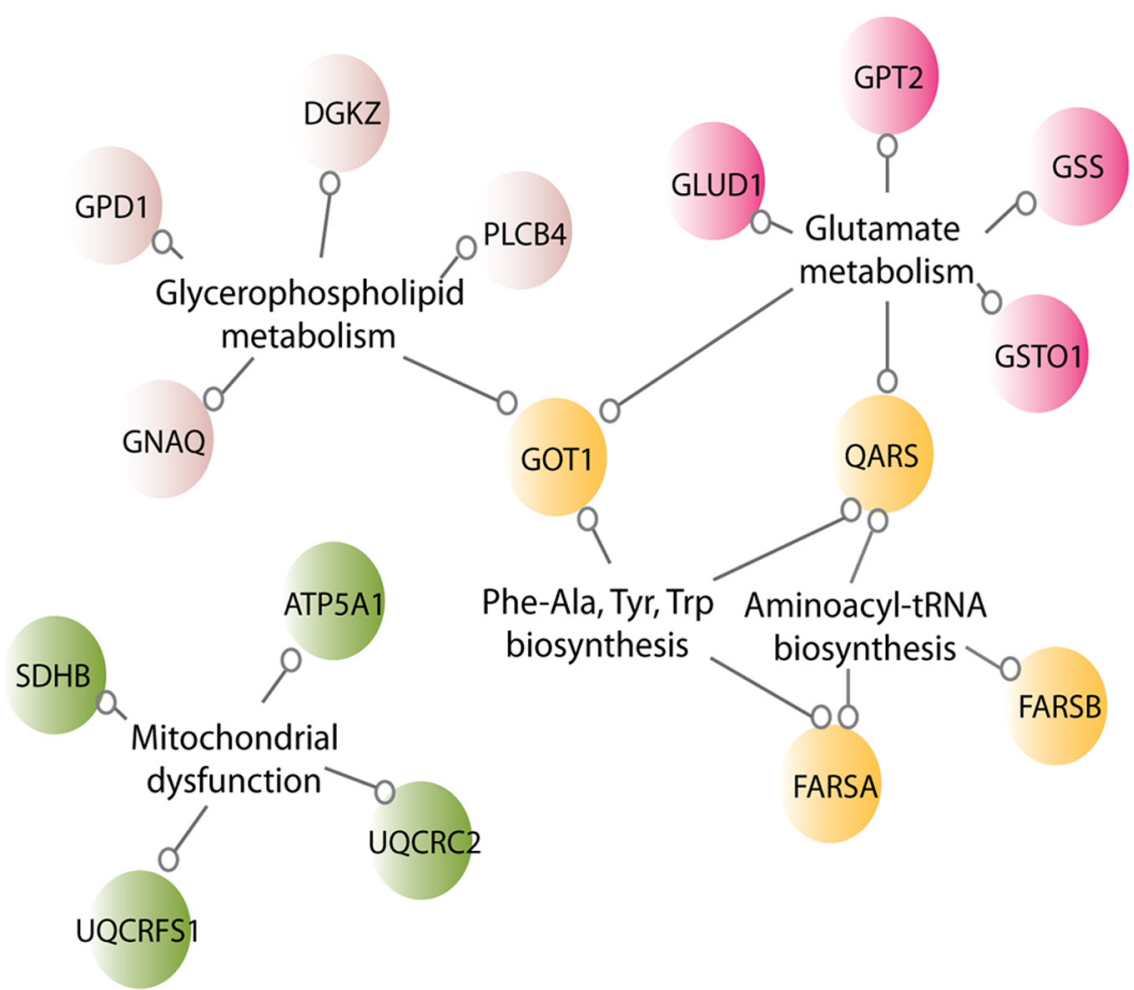

Figure 2. Protein networks upregulated $(\boldsymbol{A})$ and downregulated $(\boldsymbol{B})$ in the $R h 7^{P 37 H}$ retina, at P14.

expansion of the ER network in $R h 1^{P 37 H}$ PNs (Fig. 4C,D), indicating that misfolded Rh1 ${ }^{\mathrm{P} 37 \mathrm{H}}$ causes ER dysfunction in vivo.

We also detected a significant increase in the number of mitochondria in $R h 1^{P 37 H}$ flies relative to $R h 1^{W T}$ flies $\left(60 \% R h 1^{P 37 H}\right.$ vs $R h 1^{W T}, n=3, p<0.05$; Fig. $\left.4 a^{\prime}, b^{\prime \prime}\right)$. Moreover, highresolution images revealed that numerous mitochondria in
$R h 1^{P 37 H}$ flies displayed structural abnormalities (such as absent or poorly patterned cristae; Fig. $4 E, F$. These observations support proteomic data suggesting that Rh1 $1^{\mathrm{P} 37 \mathrm{H}}$ misfolding leads to mitochondrial failure, before the onset of retinal degeneration in $R h 1^{P 37 H}$ flies, and raise the possibility that these structural defects in mitochondrial architecture induced by $\mathrm{Rh} 1{ }^{\mathrm{P} 37 \mathrm{H}}$ toxicity contribute to PN demise. 
Finally, we also detected a strong increase in the number of autophagic vacuoles, multivesicular bodies, and lysosomes in $R h 1^{P 37 H}$ PNs (Fig. 4G,H), pinpointing to an altered autophagic degradation network in $R h 1^{P 37 H}$ PNs. Collectively, these structural analyses suggest a tight correlation between Rh1 misfolding and ER retention and dysregulation of the mitochondrial/energetic networks and the autophagic network.

\section{TOR inhibition confers robust long-term protection against $\mathrm{Rh} 1^{\mathrm{P} 37 \mathrm{H}}$ toxicity}

The differential regulation of multiple TOR targets in $\mathrm{P} 2$ versus $\mathrm{P} 14 R h 1^{\mathrm{P} 37 \mathrm{H}}$ flies prompted us to investigate the activation status of 4E-BP1 and p70S6K, two critical downstream targets of TOR signaling. A master regulator of cellular metabolism, TOR is an atypical serine/threonine kinase that is part of the phosphoinositide3-kinase-related kinase family. In mammals, mTOR recruits several adaptors to form two complexes, mTORC1 and mTORC2 (Laplante and Sabatini, 2012). mTORC1 activation promotes protein synthesis by two major mechanisms: (1) by phosphorylating and activating the p70S6 kinase (S6K kinase or p70S6K), which controls ribosome and mRNA biogenesis, translation initiation, and elongation via activation of the EIF2, EIF4B/ EIF4A, and TIF1A/Poll axes and (2) by phosphorylating the EIF4E-binding protein 1 (4E-BP1), which prevents its association with the cap-binding protein EIF4E, thereby allowing it to initiate capdependent translation (Laplante and Sabatini, 2012). Activation of the p70S6K and inhibition of $4 \mathrm{E}-\mathrm{BP} 1 / \mathrm{EIF} 4 \mathrm{E}$ activity are the most well established molecular events that occur upon mTOR activation. In Drosophila, TOR has also been shown to regulate ribosome biogenesis, translation initiation, autophagy, and cellular survival (Stanfel et al., 2009; Katewa and Kapahi, 2011).

We thus investigated the phosphorylation status of 4E-BP1 and p70S6K using specific antibodies to immunolabel retinal extracts. The levels of phosphorylated 4E-BP1 as well as p70S6K are decreased in $\mathrm{P} 2 R h 1^{P 37 H}$ retinas relative to $R h 1^{W T}$ retinas; in contrast, 4E-BP1 and p70S6K phosphorylation is increased in older (P14-P30) $R h 1^{P 37 H}$ retinas relative to $R h 1^{W T}$ retinas (Fig. $5 A, B$ ). The levels of phosphorylated 4E-BP1 were increased by $180 \%$ in P30 $R h 1^{P 37 H}$ retinas relative to $R h 1^{W T}$ retinas, while phosphop70S6K levels increased by $82 \%$ (Fig. $5 A, B$ ). The levels of total as well as phosphorylated $4 \mathrm{E}-\mathrm{BP} 1$ and $\mathrm{p} 70 \mathrm{~S} 6 \mathrm{~K}$ showed an agedependent decline in $R h 1^{W T}$ retinas, hinting to a possible adaptive response to light exposure and/or aging. The initial decrease in $4 \mathrm{E}-\mathrm{BP} 1$ and $\mathrm{p} 70 \mathrm{~S} 6 \mathrm{~K}$ signaling in young $(\mathrm{P} 2) R h 1^{P 37 H}$ retinas relative to $R h 1^{W T}$ retinas, which was reversed in older flies leading to a marked and sustained upregulation of 4E-BP1 and p70S6K

A
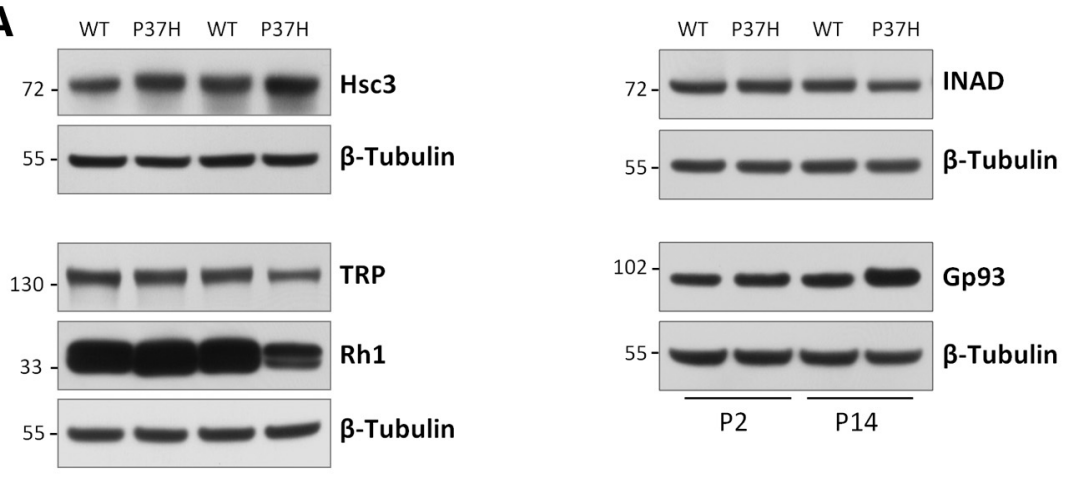

Figure 3. Validation of the proteomic results. $A$, Immunoblots showing the levels of the $\mathrm{Rh} 1$ protein; the rhabdomeric markers ( (WB; normalized to $\beta$-tubulin levels) in $R h 1^{P 37 H}$ and $R h 1^{W T}$ retinas was averaged from 50 flies per genotype and represented as percentage increase/decrease in $R h 1^{\mathrm{P} 37 \mathrm{H}}$ relative to $R h 1^{W T}$; the exact values are indicated for each protein. The percentage changes determined by MS for each protein are indicated at the bottom for comparison.

signaling (in P14-P30 Rh1 $1^{P 37 H}$ retinas) is in agreement with the inversed pattern of TOR target expression identified by MS (Table 1).

The antagonistic pattern of TOR activation in the $R h 1^{P 37 H}$ retinas of young and older flies prompted us to investigate the relevance of this signaling pathway to the process of $\mathrm{Rh} 1^{\mathrm{P} 37 \mathrm{H}_{-}}$ mediated toxicity and cellular demise. To test the effects of a chronic suppression of TOR signaling on Rh1 ${ }^{\mathrm{P} 37 \mathrm{H}}$-indued PN degeneration, we decide to employ a pharmacologic approach. We treated $R h 1^{W T}$ and $R h 1^{P 37 H}$ flies with the inhibitor rapamycin, which selectively inhibits TOR activity (Rubinsztein et al., 2007). We administered two doses of rapamycin, 50 and $200 \mu \mathrm{M}$, which were previously found to efficiently inhibit TOR signaling in Drosophila (Tain et al., 2009; Bjedov et al., 2010). As expected, rapamycin-treated $R h 1^{P 37 H}$ retinas exhibited a marked and sustained reduction in the levels of phosphorylated $4 \mathrm{E}-\mathrm{BP} 1$ and p70S6K relative to retinas from sham-treated $R h 1^{P 37 H}$ flies 

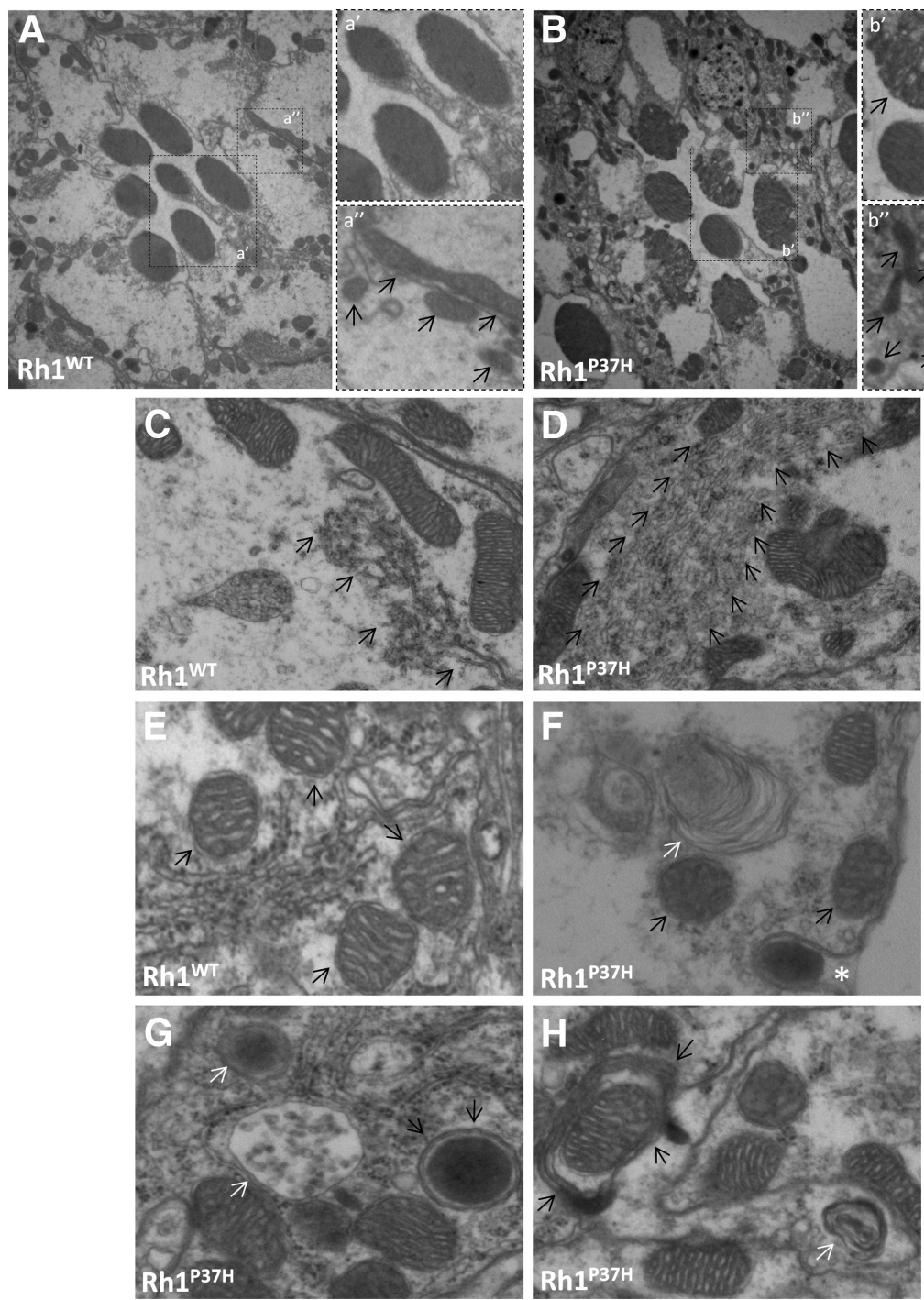

Figure 4. Misfolded $\mathrm{Rh} 1^{\mathrm{P} 37 \mathrm{H}}$ leads to altered mitochondrial structure and dynamics in vivo. $A, B$, Electron microscopy analysis of 14-d-old $R h 7^{W T}$ and $R h 7^{P 37 H}$ retinas reveals an intact ommatidial network in $R h 7^{W T}$ retinas $(\boldsymbol{A})$ and a largely preserved network in $R h 1^{P 37 H}$ retinas $(\boldsymbol{B}) . \boldsymbol{a}^{\prime}, \boldsymbol{b}^{\prime}$, Although $R h 1^{\mathrm{P}_{3} 7 \mathrm{H}}$ ommatidia display a normal set rhabdomeres, these organelles exhibit mild structural alterations $\left(\boldsymbol{b}^{\prime}\right) \cdot \boldsymbol{a}^{\prime \prime}, \boldsymbol{b}^{\prime \prime}, R h 7^{P_{3} 7 H} \mathrm{PNs}$ display an increased number of mitochondria (60\% relative to $R h 7^{W T}$; arrows). $\boldsymbol{C}, \boldsymbol{D}$ Electron microscopic analysis also reveals an expanded ER network in $R h 1^{P 37 H}$ PNs ( $\boldsymbol{D}$, arrows), consistent with a deleterious effect of $\mathrm{Rh} \mathrm{P}^{\mathrm{P} 37 \mathrm{H}}$ misfolding on ER homeostasis. $\boldsymbol{E}, \boldsymbol{F}$, higher resolution views of individual mitochondria reveals structural defects (altered or absent cristae; black arrows) in $R h 7^{P 37 H} \mathrm{PNs} . \boldsymbol{F}-\boldsymbol{H}, R h 7^{P 37 H} \mathrm{PNs}$ also exhibit numerous autophagosomes (white arrows in $\boldsymbol{G}$ ), autolysosomes (black arrows in $\boldsymbol{G}$ ), and multivesicular bodies (white arrows in $\boldsymbol{F}$ and $\boldsymbol{H}$ ), suggesting a defective autophagic degradation network.

(Fig. 5C,D) indicating that rapamycin treatment effectively inhibits TOR signaling in the $R h 1^{P 37 H}$ retina. To assess the effect of TOR signaling inhibition on $R h 1^{P 37 H}$-mediated $\mathrm{RD}$, we analyzed the retinal integrity on toluidine blue-stained eye sections. We found, remarkably, that both doses of rapamycin dramatically suppressed RD in the $R h 1^{P 37 H}$ retina (Fig. $5 E-H$ ), suggesting that TOR signaling mediates Rh1 ${ }^{\mathrm{P} 37 \mathrm{H}}$-induced $\mathrm{PN}$ cell death.

\section{The mitochondria-induced APAF-1/caspase-9 axis mediates Rh1 ${ }^{\text {P37H }}$ toxicity}

To address a potential role of mitochondria in $\mathrm{Rh} 1{ }^{\mathrm{P} 37 \mathrm{H}}$-induced cell death we used genetic analysis using several mutations that target components of the mitochondria-induced apoptosis.

We first confirmed that $\mathrm{Rh} 1^{\mathrm{P} 37 \mathrm{H}}$-induced cell death in the Drosophila compound eye proceeds via apoptosis by using mu-

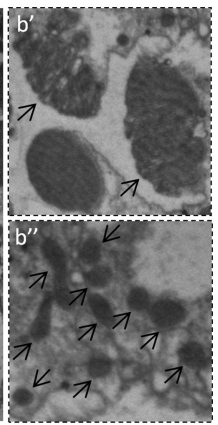

tants in which caspase-3, a central effector of apoptotic pathways, which integrates both the extracellular- and mitochondriainduced cell death signals (D'Amelio et al., 2010), is inactivated. We used the caspase-3 loss-of-function (LOF) allele Ice $\Delta 1$ referred to as Ice ${ }^{L O F}$ (Muro et al., 2006) and found that $R h 1^{P 37 H}$; Ice $e^{L O F /+}$ flies exhibit a dramatic rescue of retinal degeneration (Fig. 6C).

To assess whether mitochondria mediates cell death in $R h 1^{P 37 H}$ flies we inactivated caspase-9, which is activated specifically downstream of failing mitochondria (Diaz et al., 2006), as well as APAF-1, which interacts with procaspase- 9 to form the apoptosome, a critical activator of caspase-3 (Loudet et al., 2007; Riedl and Salvesen, 2007). We used the caspase9 LOF allele Dronc51 referred to as Dronc $^{\text {LOF }}$ (Chew et al., 2004; Waldhuber et al., 2005) and the APAF-1 LOF allele Dark82 referred to as Dark ${ }^{\text {LOF }}$ (Sang et al., 2005). We found that $R h 1^{P 37 H} ;$ Dronc $c^{L O F /+}$ and $R h 1^{P 37 H} ;$ Dark $^{L O F /+}$ flies exhibited a strong suppression of RD (Fig. 6D,E), indicating that mitochondria represent a critical link between Rh1 ${ }^{\mathrm{P} 37 \mathrm{H}}$ toxicity and PN cell death.

Class II Rho mutations fail to fold properly and exhibit increased retention in the ER (Mendes et al., 2005; Griciuc et al., 2011). Repeated cycles of folding are thought to impair the overall folding capacity of the ER and lead to ER stress, in a variety of cellular systems and organisms (Griciuc et al., 2011). Recent evidence suggests that ER stress is tightly linked to mitochondrial function (Bravo et al., 2011, 2012). We explored the possibility that chronic ER stress in $R h 1^{P 37 H}$-expressing retina causes mitochondrial dysfunction and contributes to mitochondria-induced apoptosis.

We inactivated TRAF1 and JNK, a major pathway that operates downstream of ER stress (Viornery et al., 2000) and has been found to contribute to mitochondriainduced apoptosis (Causse et al., 2002). Using the Traf1 LOF allele (Cha et al., 2003) and the JNK LOF allele $b s k 1$ (Sluss et al., 1996), we found that $R h 1^{P 37 H}$ flies carrying each of these alleles displayed a strong rescue of eye degeneration (Fig. $6 F, G)$. To further substantiate the critical role of JNK signaling, we inhibited the JNK protein using the SP600125 inhibitor, which inhibits JNK activity in a variety of cellular systems and organisms, and has been successfully used at $200 \mu \mathrm{M}$ and 1 $\mathrm{mm}$ doses to inhibit JNK activation in Drosophila (JimenezDel-Rio et al., 2008; Chen et al., 2010). Using two doses of SP600125 (200 $\mu \mathrm{M}$ and $1 \mathrm{mM}$ ), we found that preventing JNK activation strongly suppressed $\mathrm{Rh} 1^{\mathrm{P} 37 \mathrm{H}}$-induced cell death (data not shown), suggesting that the kinase activity of JNK is required for $\mathrm{Rh} 1^{\mathrm{P} 37 \mathrm{H}}$-induced cell death. These results raise the possibility that the JNK/TRAF1 axis links Rh1 ${ }^{\mathrm{P} 37 \mathrm{H}}$-induced ER stress to mitochondrial dysfunction and cell death. 
Recovery of visual responses after suppression of mitochondria-induced cell death

We sought to independently confirm the rescue of retinal integrity in $R h 1^{P 37 H}$ mutants carrying the abovementioned alleles, by measuring the electric response of the fly eye to light stimulation (electroretinogram, ERG). In this experiment, individual flies were first allowed to adapt in the dark and then subjected to a brief light stimulation. The variations of electrical potential evoked by light stimulation were recorded. Fly ERG displays photoreceptor depolarization (Plateau), which corresponds to phototransduction cascade activation, and transient spikes following initiation and cessation of the light stimulus (ON and OFF), which results from synaptic activity.

As previously reported (Galy et al., 2005; Griciuc et al., 2010b), we found that 30 -d-old $R h 1^{P 37 H}$ flies, unlike control and $R h 1^{W T}$ flies, exhibited a blunted electrical response to light stimulation (Fig. 7) consistent with their severe degenerative phenotype. Inactivation of caspase-3/Ice strongly restored visual responses (Fig. 7) in agreement with the rescue of retinal integrity. We also used $R h 1^{P 37 H}$ flies carrying the HidA206 LOF allele (referred to as Hid $\left.^{L O F}\right)$ of the head involution defective gene, a major pro-apoptotic gene in Drosophila (Sandu et al., 2010); Rh1 $1^{P 37 H}$ flies in a HidA206 mutant background exhibited a strong recovery of visual activity (Fig. 7).

Analysis of electrical responses in $R h 1^{P 37 H}$ flies carrying caspase-9/Dronc or APAF-1/Dark LOF alleles also revealed a dramatic rescue of visual functioning in agreement with our previous histological findings. Finally, inactivation of the TRAF1/JNK axis also led to a recovery of visual activity in 30-d-old $R h 1^{P 37 H}$ flies (Fig. $7)$. Collectively, these functional experiments establish the mitochondria as critical regulators of $\mathrm{Rh} 1^{\mathrm{P} 37 \mathrm{H}}$-induced cell death and raise the possibility that the TRAF1/ JNK axis provides a link between $\mathrm{Rh} 1^{\mathrm{P} 37 \mathrm{H}}$ misfolding and mitochondrial failure in PNs.

\section{Discussion}

A substantial body of literature deals with the downstream effects of chronic protein misfolding and the identity of the pathways that mediate chronic proteotoxicity and cellular demise in neurodegenerative disease. Comparatively little is known, however, about the earliest stages of the cellular response to the accumulation of misfolded proteins in neurons. Here, we used a comprehensive proteomic approach to explore the integrated cellular response to Rho misfolding and accumulation in the ER. We found an unexpected
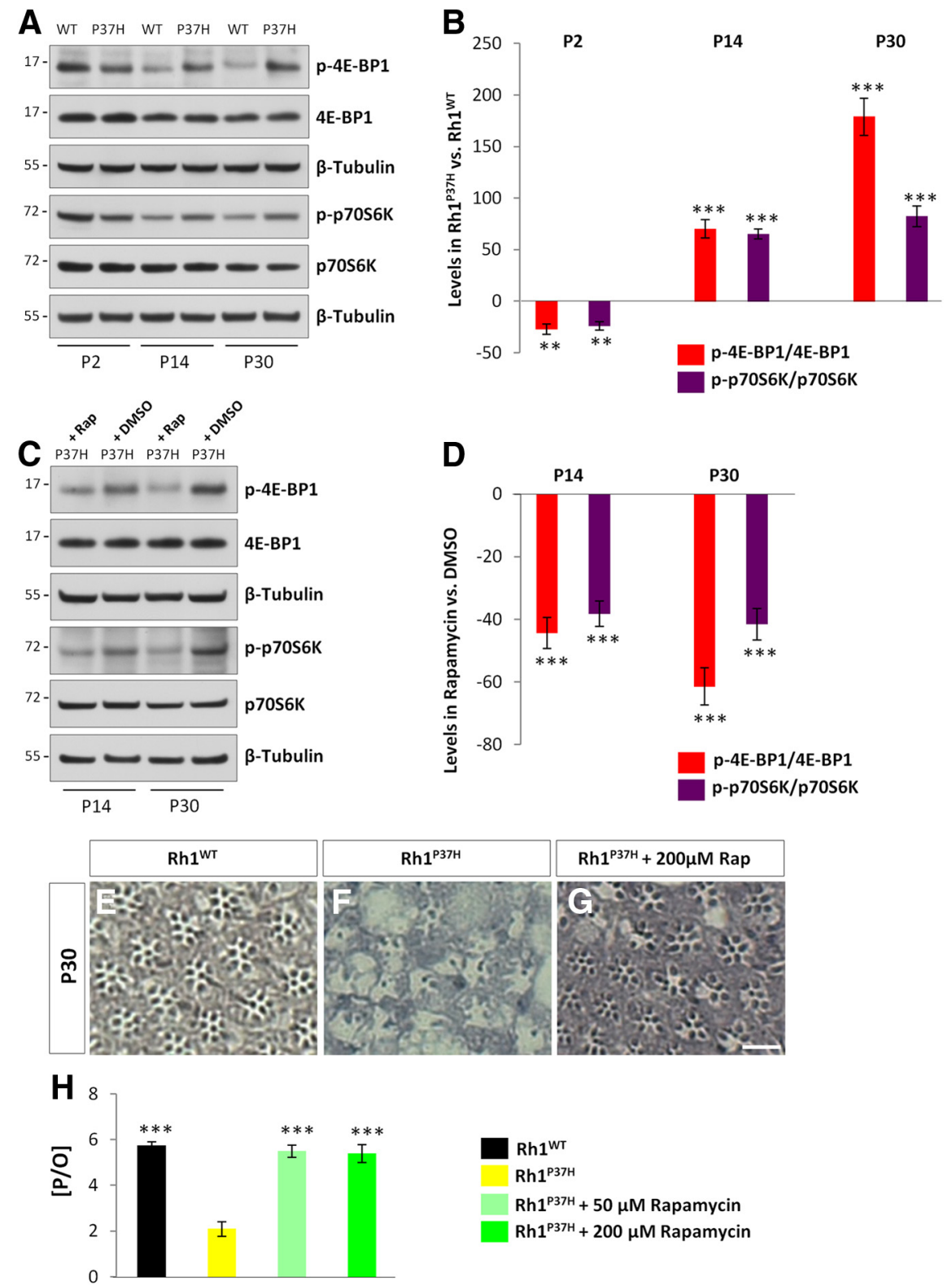

Figure 5. TOR activation mediates $\mathrm{Rh} 1^{\mathrm{P} 37 \mathrm{H}}$-induced retinal degeneration. $\boldsymbol{A}$, Immunoblots showing the levels of phosphorylated 4E-BP and phosphorylated p70S6K, as well as total 4E-BP1 and total p70S6K in retinas from P2, P14, and P30 Rh $1^{\mathrm{P} 37 \mathrm{H}}$ and $R h 1^{W T}$ flies. $\beta$-Tubulin served as loading control. B, Quantification of phospho-4E-BP1 and phospho-p70S6K levels (normalized to the levels of total 4E-BP1 and total p70S6K, respectively, as well as $\beta$-tubulin levels) in $R h 1^{P 37 H}$ and $R h 1^{W T}$ retinas; results from three independent experiments and 50 flies/genotype/experiment were averaged. Values are represented as percentage increase/ decrease in $R h 1^{\mathrm{P} 37 \mathrm{H}}$ relative to $R h 1^{W T}$. $^{* *} p<0.01$ and ${ }^{* * *} p<0.001$, Student's $t$ test. $\boldsymbol{C}$, Immunoblots showing the levels of phosphorylated 4E-BP1 and phosphorylated p70S6K, as well as total 4E-BP1 and total p70S6K in retinas from $R h 1^{P 37 H}$ flies that have been treated with $200 \mu \mathrm{m}$ rapamycin for either 14 (P14) or 30 (P30) d. $\beta$-Tubulin served as loading control. D, Quantification of phospho-4E-BP1 and phospho-p70S6K levels (normalized to the levels of total 4E-BP1 and total p70S6K, respectively, as well as $\beta$-tubulin levels); results from three independent experiments and 50 flies/genotype/experiment were averaged. Values are represented as percentage increase/decrease in rapamycin-treated $R h 1^{\mathrm{P} 37 \mathrm{H}}$ relative to sham-treated $R h 1^{\mathrm{P} 37 \mathrm{H}}$. $^{* * *} p<0.001$, Student's $t$ test. $\boldsymbol{E}-\mathbf{G}$, Photomicrographs of toluidine blue-stained eye sections of $R h 1^{W T}$ flies $(\boldsymbol{E})$ and $R h 1^{P 37 H}$ flies $(\boldsymbol{F})$ fed on control food, and of $R h 1^{P 37 H}$ flies reared on food containing $200 \mu \mathrm{m}$ rapamycin $(\boldsymbol{G})$ after $30 \mathrm{~d}$ of light exposure (P30). Scale bar, $50 \mu \mathrm{m}$. $\boldsymbol{H}$, Quantification of average number of $\mathrm{P} / 0$ ( $n>7$ animals/group, ${ }^{* * *} p<0.001 \mathrm{t}$ test). Treatment with both 50 and $200 \mu \mathrm{m}$ doses of rapamycin leads to rescue of retinal degeneration in the $R h 1^{P 37 H}$ flies.

and intimate connection between Rh1 pathology and cellular metabolism involving mitochondrial energetics and TOR signaling. Remarkably, the interplay between Rh1 proteotoxicity and these aspects of metabolism is subject to change as the organism ages, such that the relationships seen after chronic exposure to Rh1 misfolding (P14 retina) are the opposite of those seen after a more acute expo- 

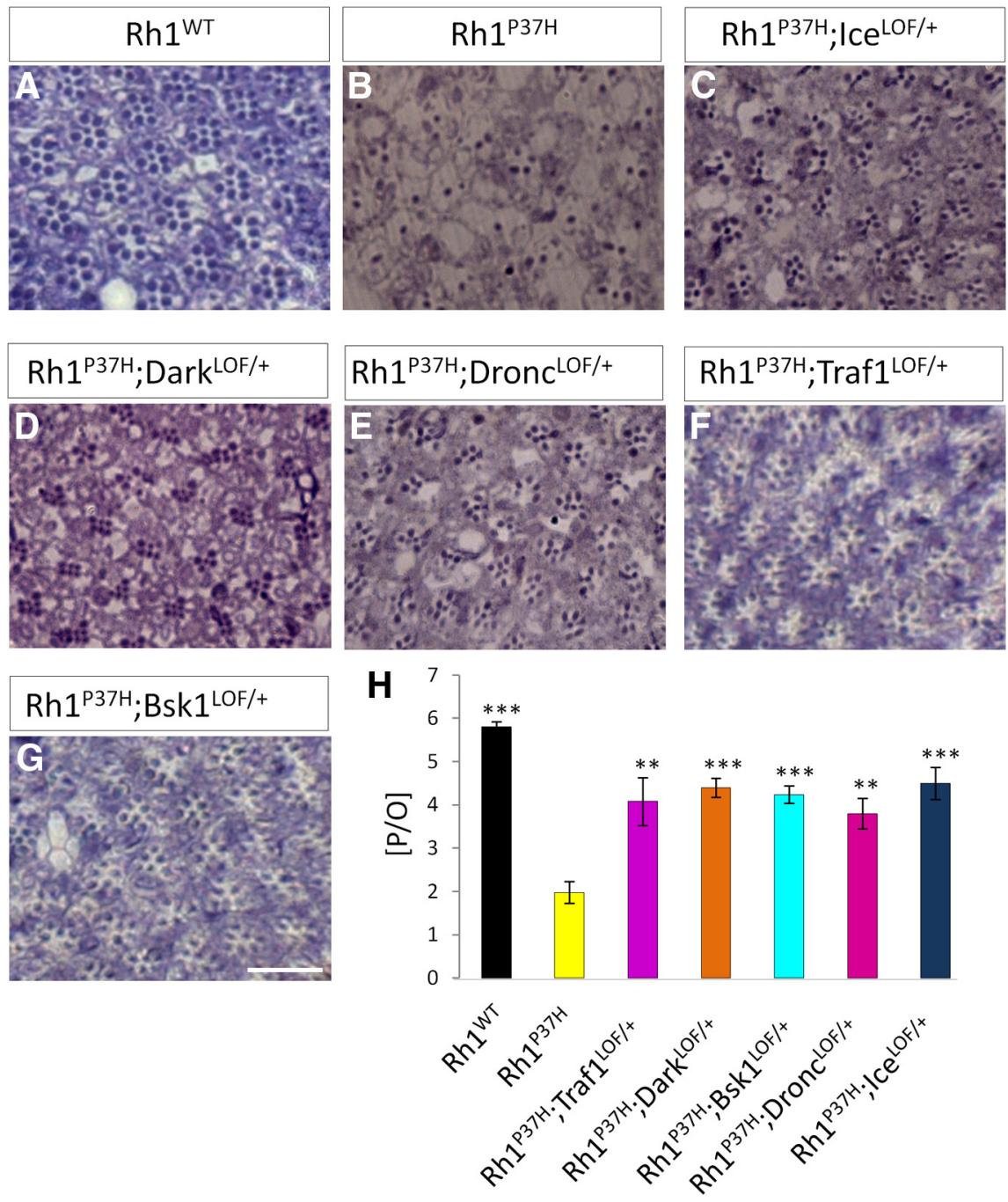

Figure 6. Suppression of $\mathrm{Rh} 1^{\mathrm{P} 37 \mathrm{H}}$-induced retinal degeneration by genetic inactivation of the APAF-1/caspase- 9 and Traf1/JNK

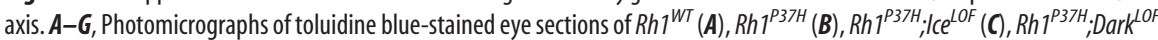

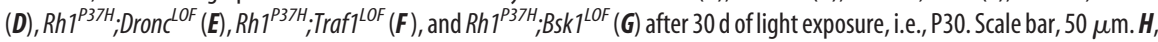
Quantification of average number of $\mathrm{P} / 0\left(n>7\right.$ animals/group, ${ }^{* *} p<0.01$ and ${ }^{* * *} p<0.001 t$ test). Genetic inactivation of Ice/caspase- 3 and of the APAF-1/caspase- 9 axis (Dark and Dronc) potently suppresses retinal degeneration caused by Rh1 ${ }^{\mathrm{P} 37 \mathrm{H}}$ Inactivation of the TRAF1/JNK axis (Traf1, Bsk1) also leads to rescue of retinal degeneration in the $R h 1^{P 37 H}$ retina.

sure to $\mathrm{Rh} 1^{\mathrm{P} 37 \mathrm{H}}$ (P2 retina). Complementary mechanistic studies, using pharmacological and genetic approaches, further substantiated the critical link between mitochondrial- and TOR-mediated metabolic processes and Rh1 ${ }^{\mathrm{P} 37 \mathrm{H}}$ toxicity in PNs. We thus propose that chronic metabolic stress and metabolic failure are novel effectors of Rh1 ${ }^{\mathrm{P} 37 \mathrm{H}}$ pathology in PNs and might represent important cellular targets in RP.

\section{Chronic activation of TOR signaling promotes $\mathrm{Rh} 1^{\mathrm{P} 37 \mathrm{H}_{-}}$ induced cell death}

Mounting evidence suggests a critical role for the interaction between ER stress and mTOR signaling in physiology and disease (Appenzeller-Herzog and Hall, 2012). In many physiological situations, the ER stress and mTOR signaling elicit opposite effects in cells: while the former promotes energy consumption, inhibits ribosome biogenesis and translation initiation, and promotes autophagy and cell death; the latter has the opposite effect on these processes (Hoyer-Hansen and Jäättelä, 2007; Rutkowski and
Hegde, 2010; Zoncu et al., 2011; Appenzeller-Herzog and Hall, 2012).

Whether mTOR signaling promotes or prevents neurodegeneration might depend on the metabolic status of PNs. We detected a sustained upregulation of TOR signaling in the $R h 1^{P 37 H}$ retina, which was detected at the onset of RD (P14) and was maintained thereafter (Fig. 5A,B). P14 $R h 1^{P 37 H}$ retinas also exhibited mitochondrial structural defects and altered energetic patterns. The dramatic rescue of $\mathrm{RD}$ after rapamycin treatment (Fig. $5 E-H$ ) suggests that TOR signaling mediates ER stress-induced cell death in the $R h 1^{P 37 H}$ retina. Mounting evidence suggests that mTOR mediates apoptosis downstream of ER stress, in certain pathological situations (Appenzeller-Herzog and Hall, 2012). mTOR activation by chronic ER stress suppresses the phosphorylation of the prosurvival Akt kinase, an upstream negative regulator of the Ire1-ASK1-JNK pathway (Kato et al., 2012). Moreover, rescue of misfolded Rho ${ }^{\text {T17M }}$-induced RD in mice by caspase-7 ablation was associated with reprogramming of ER stressassociated gene expression, decreased mTOR expression, and attenuation of JNK signaling (Choudhury et al., 2013).

In contrast to these pro-apoptotic functions, mTOR was suggested to promote survival of nutrient-deprived cone PNs (Punzo et al., 2009). Cone photoreceptor starvation was shown to be a common feature of several models of RP, which also displayed reduced levels of activated (phosphorylated) mTOR during PN degeneration. Systemic insulin treatment mitigated cone degeneration in one of these models (the Pde6 $6 b^{-/-}$mouse); this effect was attributed to the activation of mTOR signaling by insulin and the subsequent mTOR-mediated autophagy inhibition, which would prevent an energetic crisis in cones (Punzo et al., 2009). However, insulin is also a key activator of prosurvival signaling pathways, including the Akt kinase-a major anti-apoptotic mediator. It remains to be determined whether mTOR signaling activation by insulin is neuroprotective in this model, or whether other mTORindependent, insulin-mediated signaling pathways mediate this neuroprotective effect. It also remains to be determined whether the observed downregulation of mTOR signaling during PN degeneration was pathogenic or represented a prosurvival compensatory response. This study raises the interesting possibility that the effects of mTOR signaling on PN survival might be dependent on the metabolic status of PNs and the overall cellular energetic profile, a possibility that could be addressed by future studies.

Our present findings suggest that the ER stress/mTOR/JNK axis represents a critical link between chronic Rho proteotoxicity and PN demise in RP. A better understanding of the connection between the nutritional/metabolic status of PNs and the activa- 
tion of the ER stress/mTOR/JNK axis might uncover important cellular targets and provide novel therapeutic approaches for RP.

\section{Failing mitochondria mediate Rh1 ${ }^{\text {P37H }}$ toxicity}

The present study identifies mitochondria as central regulators of chronic Rh1 ${ }^{\mathrm{P} 37 \mathrm{H}}$ proteotoxicity in PNs. We found an early acceleration of anaerobic and aerobic catabolism and mitochondrial energy production; this pattern was reversed before the onset of RD. Mitochondrial respiration is a major source of reactive oxygen species (ROS) and increased mitochondrial function leads to excess ROS production, should antioxidant systems fail to neutralize newly generated ROS (Sena and Chandel, 2012). Consistent with this, signaling by NRF2, the master regulator of oxidative stress responses in the cell, was increased in $R h 1^{P 37 H}$ retinas at the onset of $\mathrm{RD}$; moreover, electron microscopic analysis of PNs revealed numerous mitochondria with defective cristae in $\mathrm{P} 14 R h 1^{P 37 H}$ flies (Fig. 4), suggesting the existence of oxidative stress and oxidative damage in the $R h 1^{P 37 H}$ retina. These observations are consistent with a model whereby misfolded $\mathrm{Rh} 1^{\mathrm{P} 37 \mathrm{H}}$ alters mitochondrial function, leading to the generation of oxidative stress and to mitochondrial damage.

Severely damaged mitochondria are potent activators of the apoptotic program; the highly conserved APAF-1/ caspase-9 pathway represents a central link between failing mitochondria and executioner caspase activation (Riedl and Salvesen, 2007). Remarkably, inactivation of the APAF-1/caspase- 9 axis dramatically suppressed $R h 1^{P 37 H}$-induced RD, identifying the damaged mitochondria as novel mediators of $\mathrm{Rh} 1^{\mathrm{P} 37 \mathrm{H}}$ toxicity.

Defective communication between the ER and mitochondria is increasingly recognized as a pathogenic event in disease (Raturi and Simmen, 2013). To begin addressing whether the dysfunctional ER leads to mitochondrial pathology via activation of ER stress signaling in our $R h 1^{P 37 H}$ model of RP, we genetically inactivated the TRAF1/JNK axis, a well established mediator of ER stress (Ron and Walter, 2007). JNK signaling is enhanced in the $R h 1^{P 37 H}$ retina (Galy et al., 2005), but whether it directly contributes to Rh1 $1^{\mathrm{P} 37 \mathrm{H}}$-induced apoptosis remained unknown. Genetic inactivation of JNK or TRAF1 strongly mitigated Rh1 ${ }^{\mathrm{P} 37 \mathrm{H}}$ toxicity (Figs. 6, 7) as did the pharmacological inhibition of JNK kinase activity using the specific inhibitor SP600125 (data not shown). Therefore, the kinase activity of JNK is required for Rh1 ${ }^{\mathrm{P} 37 \mathrm{H}}$ induced apoptosis, and TRAF1 might represent the link between ER stress and JNK activation in the $R h 1^{P 37 H}$ retina.

Drugs that limit the deleterious effects of mitochondrial failure and caspase activation emerge as important drug targets in RP. The caspase-3 inhibitor Ac-DEVD-CHO transiently delays
$\mathrm{RD}$ in the $r d$ mouse (Yoshizawa et al., 2002); adeno-associated virus-mediated delivery of the X-linked inhibitor of apoptosiswhich inhibits caspases-3, -7, and -9-protected PNs in the $R h o^{P 23 H}$ and $R h o^{\text {S334ter }}$ rat models of RP (Leonard et al., 2007); caspase-7 inhibition also mitigated RD in the $R h o^{T 17 M}$ mouse (Choudhury et al., 2013). Inhibitors of the APAF-1/caspase-9 axis identified in the present study could be tested in future studies.

PNs are among the most energy-consuming cell types in the organism. Based on our findings that mitochondrial and metabolic abnormalities are a central component of $\mathrm{Rh} 1^{\mathrm{P} 37 \mathrm{H}}$ toxicity, we surveyed the $\mathrm{RD}$-linked genes and established that 13 genes that are functionally characterized play a role in cellular metabolism; moreover, chromosomal deletions that inactivate several respiratory chain components also cause $\mathrm{RD}$ (Table 2). It is interesting to note that inactivation of several mitochondrially encoded transfer RNAs cause defective mitochondrial respiration and RD in humans. We also detected a downregulation of glutaminyl-tRNA, phenylalanyltRNA, and phenylalanyl-tRNA synthetase subunits in 14-d-old $R h 1^{P 37 H}$ flies (Table 1). Thus, impaired amino acid synthesis might 


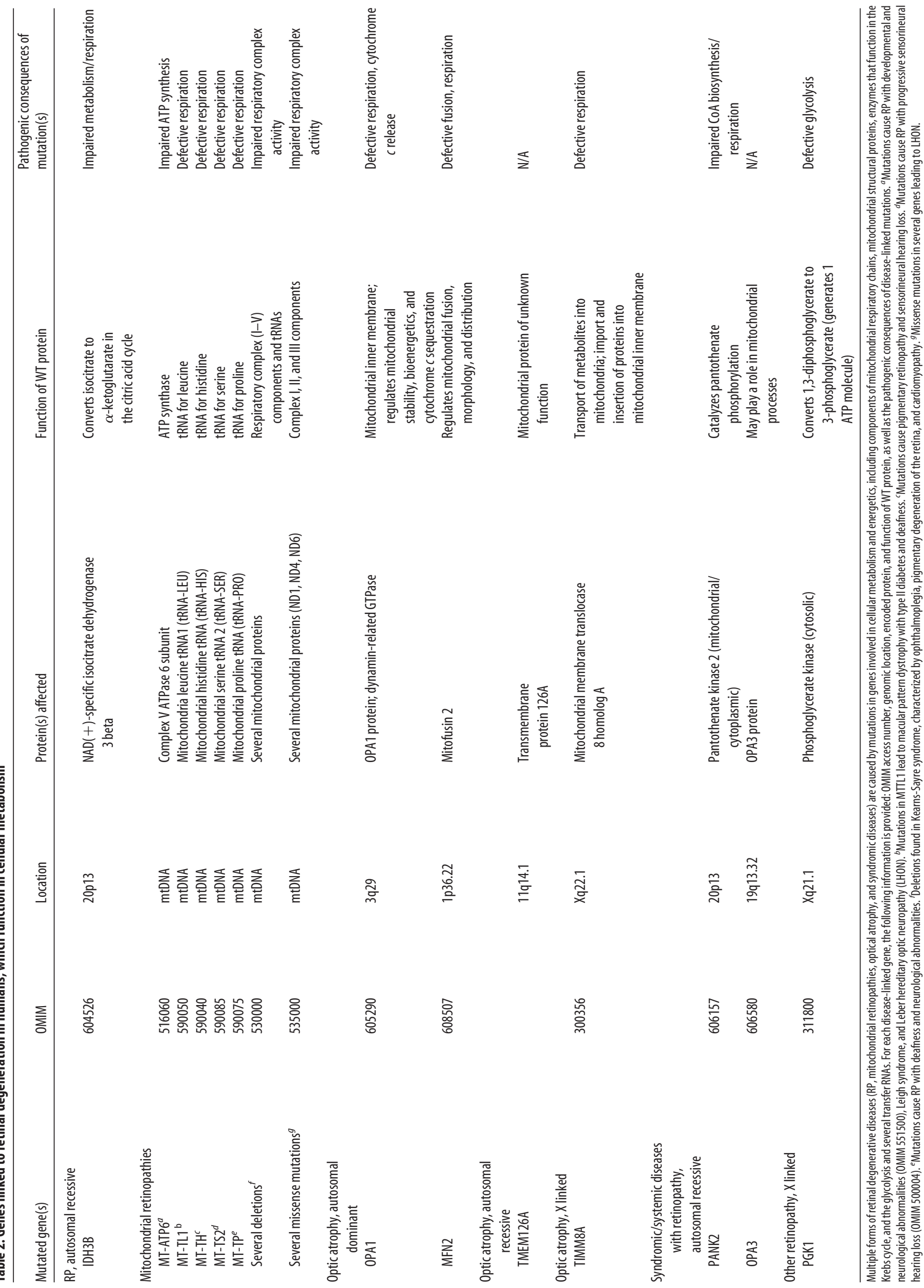




\section{misfolded Rh1 ${ }^{\text {P37H }}$}

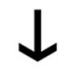

\section{Early ( 2 days)}

\section{Adaptive (pro-survival) changes}

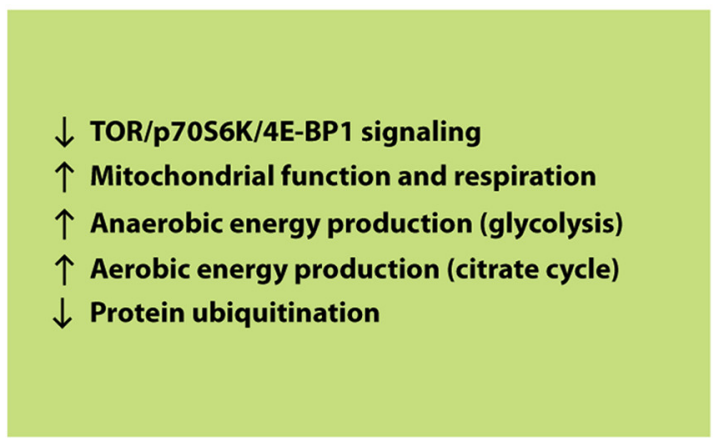

Metabolic adaptation

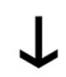

Late (14 days)

\section{Pathogenic (pro-apoptotic) changes}

$\uparrow$ TOR/p70S6K/4E-BP1 signaling

$\downarrow$ Mitochondrial function and respiration

$\downarrow$ Glutamate metabolism, amino acid synthesis

$\uparrow$ Caveolar-mediated endocytosis

$\uparrow$ NRF2-mediated oxidative stress response

Mitochondrial structural defects

\section{Metabolic failure}

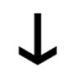

\section{Apoptosis:}

\section{TOR-mediated \\ JNK-mediated \\ caspase-9/APAF1-mediated}

Figure 8. Model of $\mathrm{Rh} 1^{\mathrm{P} 37 \mathrm{H}}$-induced metabolic failure in PNs (see text for details). amplify Rh1 ${ }^{\mathrm{P} 37 \mathrm{H}}$ toxicity in fly PNs, a possibility that could be addressed by future studies.

A model of metabolic failure in $\mathrm{Rh} 1{ }^{\mathrm{P} 37 \mathrm{H}}$-linked RD

Neurodegenerative diseases, such as Alzheimer's disease, Parkinson's disease, or RP, are chronic proteinopathies, whereby the presence of misfolded proteins induces long-term cellular alterations culminating with the demise of specific neuronal populations. It is currently unknown why such diseases only manifest after decades, although folding-deficient proteins are expressed early in life. We suggest that the breakdown of cellular homeostasis in RP is the result of the long-term modification of cellular metabolic and energetics output by misfolded Rho. Based on the present data, we propose that PN loss in the $R h 1^{P 37 H}$ fly model of $\mathrm{RP}$ is a two-step process in which an early, compensatory phase is followed by a late pro-apoptotic phase of metabolic dysregulation (Fig. 8). We believe the chronic presence of misfolded $\mathrm{Rh} 1^{\mathrm{P} 37 \mathrm{H}}$ in the ER and the highly energetic processes of Rh1 folding and ERAD ultimately lead to loss of energetic capacity and metabolic stress that culminate with PN cell death. This model underscores the importance of early compensatory changes in PNs and suggests that preventing high-anabolic states in PNs (by, for example, decreasing mTOR activity) might prevent energy crises and afford long-term protection against $\mathrm{Rh} 1{ }^{\mathrm{P} 37 \mathrm{H}}$ toxicity. More generally, therapies effective at restoring metabolic function in PNs might be able to prevent or delay RP.

\section{References}

Abou-Sleiman PM, Muqit MM, Wood NW (2006) Expanding insights of mitochondrial dysfunction in Parkinson's disease. Nat Rev Neurosci 7:207-219. CrossRef Medline

Appenzeller-Herzog C, Hall MN (2012) Bidirectional crosstalk between endoplasmic reticulum stress and mTOR signaling. Trends Cell Biol 22: 274-282. CrossRef Medline

Bantscheff M, Schirle M, Sweetman G, Rick J, Kuster B (2007) Quantitative mass spectrometry in proteomics: a critical review. Anal Bioanal Chem 389:1017-1031. CrossRef Medline

Bjedov I, Toivonen JM, Kerr F, Slack C, Jacobson J, Foley A, Partridge L (2010) Mechanisms of life span extension by rapamycin in the fruit fly Drosophila melanogaster. Cell Metab 11:35-46. CrossRef Medline

Bramall AN, Wright AF, Jacobson SG, McInnes RR (2010) The genomic, biochemical, and cellular responses of the retina in inherited photoreceptor degenerations and prospects for the treatment of these disorders. Annu Rev Neurosci 33:441-472. CrossRef Medline

Bravo R, Vicencio JM, Parra V, Troncoso R, Munoz JP, Bui M, Quiroga C, Rodriguez AE, Verdejo HE, Ferreira J, Iglewski M, Chiong M, Simmen T, Zorzano A, Hill JA, Rothermel BA, Szabadkai G, Lavandero S (2011) Increased ER-mitochondrial coupling promotes mitochondrial respiration and bioenergetics during early phases of ER stress. J Cell Sci 124: 2143-2152. CrossRef Medline

Bravo R, Gutierrez T, Paredes F, Gatica D, Rodriguez AE, Pedrozo Z, Chiong M, Parra V, Quest AF, Rothermel BA, Lavendero S (2012) Endoplasmic reticulum: ER stress regulates mitochondrial bioenergetics. Int J Biochem Cell Biol 44:16-20. CrossRef Medline

Causse M, Saliba-Colombani V, Lecomte L, Duffé P, Rousselle P, Buret M (2002) QTL analysis of fruit quality in fresh market tomato: a few chromosome regions control the variation of sensory and instrumental traits. J Exp Bot 53:2089-2098. CrossRef Medline

Cha GH, Cho KS, Lee JH, Kim M, Kim E, Park J, Lee SB, Chung J (2003) Discrete functions of TRAF1 and TRAF2 in Drosophila melanogaster mediated by c-Jun N-terminal kinase and NF-kappaB-dependent signaling pathways. Mol Cell Biol 23:7982-7991. CrossRef Medline

Chen J, Xie C, Tian L, Hong L, Wu X, Han J (2010) Participation of the p38 pathway in Drosophila host defense against pathogenic bacteria and fungi. Proc Natl Acad Sci U S A 107:20774-20779. CrossRef Medline

Chew SK, Akdemir F, Chen P, Lu WJ, Mills K, Daish T, Kumar S, Rodriguez A, Abrams JM (2004) The apical caspase dronc governs programmed and unprogrammed cell death in Drosophila. Dev Cell 7:897-907. CrossRef Medline 
Choudhury S, Bhootada Y, Gorbatyuk O, Gorbatyuk M (2013) Caspase-7 ablation modulates UPR, reprograms TRAF2-JNK apoptosis and protects T17M rhodopsin mice from severe retinal degeneration. Cell Death Dis 4:e528. CrossRef Medline

Colley NJ, Cassill JA, Baker EK, Zuker CS (1995) Defective intracellular transport is the molecular basis of rhodopsin-dependent dominant retinal degeneration. Proc Natl Acad Sci U S A 92:3070-3074. CrossRef Medline

Cox J, Mann M (2008) MaxQuant enables high peptide identification rates, individualized p.p.b.-range mass accuracies and proteome-wide protein quantification. Nat Biotechnol 26:1367-1372. CrossRef Medline

Cox J, Matic I, Hilger M, Nagaraj N, Selbach M, Olsen JV, Mann M (2009) A practical guide to the MaxQuant computational platform for SILACbased quantitative proteomics. Nat Protoc 4:698-705. CrossRef Medline

Cox J, Neuhauser N, Michalski A, Scheltema RA, Olsen JV, Mann M (2011) Andromeda: a peptide search engine integrated into the MaxQuant environment. J Proteome Res 10:1794-1805. CrossRef Medline

Daiger SP, Bowne SJ, Sullivan LS (2007) Perspective on genes and mutations causing retinitis pigmentosa. Arch Ophthalmol 125:151-158. CrossRef Medline

D’Amelio M, Cavallucci V, Cecconi F (2010) Neuronal caspase-3 signaling: not only cell death. Cell Death Differ 17:1104-1114. CrossRef Medline

Diaz C, Saliba-Colombani V, Loudet O, Belluomo P, Moreau L, DanielVedele F, Morot-Gaudry JF, Masclaux-Daubresse C (2006) Leaf yellowing and anthocyanin accumulation are two genetically independent strategies in response to nitrogen limitation in Arabidopsis thaliana. Plant Cell Physiol 47:74-83. Medline

Galy A, Roux MJ, Sahel JA, Léveillard T, Giangrande A (2005) Rhodopsin maturation defects induce photoreceptor death by apoptosis: a fly model for RhodopsinPro23His human retinitis pigmentosa. Hum Mol Genet 14:2547-2557. CrossRef Medline

Griciuc A, Aron L, Piccoli G, Ueffing M (2010a) Clearance of Rhodopsin(P23H) aggregates requires the ERAD effector VCP. Biochim Biophys Acta 1803:424434. CrossRef Medline

Griciuc A, Aron L, Roux MJ, Klein R, Giangrande A, Ueffing M (2010b) Inactivation of $\mathrm{VCP} /$ ter94 suppresses retinal pathology caused by misfolded rhodopsin in Drosophila. PLoS Genet 6:e1001075. CrossRef Medline

Griciuc A, Aron L, Ueffing M (2011) ER stress in retinal degeneration: a target for rational therapy? Trends Mol Med 17:442-451. CrossRef Medline

Griciuc A, Aron L, Ueffing M (2012) Looking into eyes: rhodopsin pathologies in Drosophila. Adv Exp Med Biol 723:415-423. CrossRef Medline

Hauck SM, Dietter J, Kramer RL, Hofmaier F, Zipplies JK, Amann B, Feuchtinger A, Deeg CA, Ueffing M (2010) Deciphering membrane-associated molecular processes in target tissue of autoimmune uveitis by label-free quantitative mass spectrometry. Mol Cell Proteomics 9:2292-2305. CrossRef Medline

Hoyer-Hansen M, Jäättelä M (2007) Connecting endoplasmic reticulum stress to autophagy by unfolded protein response and calcium. Cell Death Differ 14:1576-1582. CrossRef Medline

Illing ME, Rajan RS, Bence NF, Kopito RR (2002) A rhodopsin mutant linked to autosomal dominant retinitis pigmentosa is prone to aggregate and interacts with the ubiquitin proteasome system. J Biol Chem 277: 34150-34160. CrossRef Medline

Jimenez-Del-Rio M, Daza-Restrepo A, Velez-Pardo C (2008) The cannabinoid CP55,940 prolongs survival and improves locomotor activity in Drosophila melanogaster against paraquat: implications in Parkinson's disease. Neurosci Res 61:404-411. CrossRef Medline

Kapahi P, Chen D, Rogers AN, Katewa SD, Li PW, Thomas EL, Kockel L (2010) With TOR, less is more: a key role for the conserved nutrientsensing TOR pathway in aging. Cell Metab 11:453-465. CrossRef Medline

Katewa SD, Kapahi P (2011) Role of TOR signaling in aging and related biological processes in Drosophila melanogaster. Exp Gerontol 46:382390. CrossRef Medline

Kato H, Nakajima S, Saito Y, Takahashi S, Katoh R, Kitamura M (2012) mTORC1 serves ER stress-triggered apoptosis via selective activation of the IRE1-JNK pathway. Cell Death Differ 19:310-320. CrossRef Medline

Kensler TW, Wakabayashi N, Biswal S (2007) Cell survival responses to environmental stresses via the Keap1-Nrf2-ARE pathway. Annu Rev Pharmacol Toxicol 47:89-116. CrossRef Medline
Laplante M, Sabatini DM (2012) mTOR signaling in growth control and disease. Cell 149:274-293. CrossRef Medline

Lee SJ, Montell C (2004) Suppression of constant-light-induced blindness but not retinal degeneration by inhibition of the rhodopsin degradation pathway. Curr Biol 14:2076-2085. CrossRef Medline

Leonard KC, Petrin D, Coupland SG, Baker AN, Leonard BC, LaCasse EC, Hauswirth WW, Korneluk RG, Tsilfidis C (2007) XIAP protection of photoreceptors in animal models of retinitis pigmentosa. PLoS One 2:e314. CrossRef Medline

Lizcano JM, Alrubaie S, Kieloch A, Deak M, Leevers SJ, Alessi DR (2003) Insulin-induced Drosophila S6 kinase activation requires phosphoinositide 3-kinase and protein kinase B. Biochem J 374:297-306. CrossRef Medline

Loudet O, Saliba-Colombani V, Camilleri C, Calenge F, Gaudon V, Koprivova A, North KA, Kopriva S, Daniel-Vedele F (2007) Natural variation for sulfate content in Arabidopsis thaliana is highly controlled by APR2. Nat Genet 39:896-900. CrossRef Medline

Maynard JC, Pham T, Zheng T, Jockheck-Clark A, Rankin HB, Newgard CB, Spana EP, Nicchitta CV (2010) Gp93, the Drosophila GRP94 ortholog, is required for gut epithelial homeostasis and nutrient assimilationcoupled growth control. Dev Biol 339:295-306. CrossRef Medline

Mendes HF, van der Spuy J, Chapple JP, Cheetham ME (2005) Mechanisms of cell death in rhodopsin retinitis pigmentosa: implications for therapy. Trends Mol Med 11:177-185. CrossRef Medline

Merl J, Ueffing M, Hauck SM, von Toerne C (2012) Direct comparison of MS-based label-free and SILAC quantitative proteome profiling strategies in primary retinal Muller cells. Proteomics 12:1902-1911. CrossRef Medline

Muro I, Berry DL, Huh JR, Chen CH, Huang H, Yoo SJ, Guo M, Baehrecke EH, Hay BA (2006) The Drosophila caspase Ice is important for many apoptotic cell deaths and for spermatid individualization, a nonapoptotic process. Development 133:3305-3315. CrossRef Medline

Punzo C, Kornacker K, Cepko CL (2009) Stimulation of the insulin/mTOR pathway delays cone death in a mouse model of retinitis pigmentosa. Nat Neurosci 12:44-52. CrossRef Medline

Raturi A, Simmen T (2013) Where the endoplasmic reticulum and the mitochondrion tie the knot: the mitochondria-associated membrane (MAM). Biochim Biophys Acta 1833:213-224. CrossRef Medline

Raught B, Gingras AC, Gygi SP, Imataka H, Morino S, Gradi A, Aebersold R, Sonenberg N (2000) Serum-stimulated, rapamycin-sensitive phosphorylation sites in the eukaryotic translation initiation factor 4GI. EMBO J 19:434-444. CrossRef Medline

Riedl SJ, Salvesen GS (2007) The apoptosome: signalling platform of cell death. Nat Rev Mol Cell Biol 8:405-413. CrossRef Medline

Ron D, Walter P (2007) Signal integration in the endoplasmic reticulum unfolded protein response. Nat Rev Mol Cell Biol 8:519-529. CrossRef Medline

Rosenbaum EE, Hardie RC, Colley NJ (2006) Calnexin is essential for rhodopsin maturation, $\mathrm{Ca} 2+$ regulation, and photoreceptor cell survival. Neuron 49:229-241. CrossRef Medline

Rubinsztein DC, Gestwicki JE, Murphy LO, Klionsky DJ (2007) Potential therapeutic applications of autophagy. Nat Rev Drug Discov 6:304-312. CrossRef Medline

Rutkowski DT, Hegde RS (2010) Regulation of basal cellular physiology by the homeostatic unfolded protein response. J Cell Biol 189:783-794. CrossRef Medline

Ryoo HD, Domingos PM, Kang MJ, Steller H (2007) Unfolded protein response in a Drosophila model for retinal degeneration. EMBO J 26:242252. CrossRef Medline

Sakami S, Maeda T, Bereta G, Okano K, Golczak M, Sumaroka A, Roman AJ, Cideciyan AV, Jacobson SG, Palczewski K (2011) Probing mechanisms of photoreceptor degeneration in a new mouse model of the common form of autosomal dominant retinitis pigmentosa due to $\mathrm{P} 23 \mathrm{H}$ opsin mutations. J Biol Chem 286:10551-10567. CrossRef Medline

Saliba RS, Munro PM, Luthert PJ, Cheetham ME (2002) The cellular fate of mutant rhodopsin: quality control, degradation and aggresome formation. J Cell Sci 115:2907-2918. Medline

Sandu C, Ryoo HD, Steller H (2010) Drosophila IAP antagonists form multimeric complexes to promote cell death. J Cell Biol 190:1039-1052. CrossRef Medline

Sang TK, Li C, Liu W, Rodriguez A, Abrams JM, Zipursky SL, Jackson GR (2005) Inactivation of Drosophila Apaf-1 related killer suppresses for- 
mation of polyglutamine aggregates and blocks polyglutamine pathogenesis. Hum Mol Genet 14:357-372. Medline

Sena LA, Chandel NS (2012) Physiological roles of mitochondrial reactive oxygen species. Mol Cell 48:158-167. CrossRef Medline

Sluss HK, Han Z, Barrett T, Goberdhan DC, Wilson C, Davis RJ, Ip YT (1996) A JNK signal transduction pathway that mediates morphogenesis and an immune response in Drosophila. Genes Dev 10:2745-2758. CrossRef Medline

Stanfel MN, Shamieh LS, Kaeberlein M, Kennedy BK (2009) The TOR pathway comes of age. Biochim Biophys Acta 1790:1067-1074. CrossRef Medline

Tain LS, Mortiboys H, Tao RN, Ziviani E, Bandmann O, Whitworth AJ (2009) Rapamycin activation of 4E-BP prevents parkinsonian dopaminergic neuron loss. Nat Neurosci 12:1129-1135. CrossRef Medline

Thiele T, Iuga C, Janetzky S, Schwertz H, Gesell Salazar M, Furll B, Volker U, Greinacher A, Steil L (2012) Early storage lesions in apheresis platelets are induced by the activation of the integrin alphaII(b)beta(3) and focal adhesion signaling pathways. J Proteomics 76:297-315. CrossRef Medline

Thoreen CC, Chantranupong L, Keys HR, Wang T, Gray NS, Sabatini DM (2012) A unifying model for mTORC1-mediated regulation of mRNA translation. Nature 485:109-113. CrossRef Medline
Viornery L, Saliba C, Daskiewicz JB, Bayet C, Comte G, Fenet B, Gutierrez G, Barron D (2000) Phenylpropanoids from Umbilicus pendulinus. Chem Pharm Bull 48:1768-1770. CrossRef Medline

Voolstra O, Beck K, Oberegelsbacher C, Pfannstiel J, Huber A (2010) Lightdependent phosphorylation of the drosophila transient receptor potential ion channel. J Biol Chem 285:14275-14284. CrossRef Medline

Waldhuber M, Emoto K, Petritsch C (2005) The Drosophila caspase DRONC is required for metamorphosis and cell death in response to irradiation and developmental signals. Mech Dev 122:914-927. CrossRef Medline

Wright AF, Chakarova CF, Abd El-Aziz MM, Bhattacharya SS (2010) Photoreceptor degeneration: genetic and mechanistic dissection of a complex trait. Nat Rev Genet 11:273-284. CrossRef Medline

Yoshizawa K, Kiuchi K, Nambu H, Yang J, Senzaki H, Kiyozuka Y, Shikata N, Tsubura A (2002) Caspase-3 inhibitor transiently delays inherited retinal degeneration in $\mathrm{C} 3 \mathrm{H}$ mice carrying the rd gene. Graefes Arch Clin Exp Ophthalmol 240:214-219. CrossRef Medline

Zoncu R, Efeyan A, Sabatini DM (2011) mTOR: from growth signal integration to cancer, diabetes and ageing. Nat Rev Mol Cell Biol 12:21-35. CrossRef Medline 